\title{
LE VIRTÙ E LE IMPRESE DI MENIPPO E DEI SUOI COLLEGHI NELLA SATIRA DI LUCIANO
}

\author{
Alberto Camerotto* \\ Università Ca' Foscari Venezia

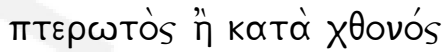 \\ Eur. Herc. 1157
}

\begin{abstract}
RESUMO: As personagens que, na obra de Luciano de Samósata, representam a voz da sátira têm virtudes especiais do ser, do fazer, do ver e do dizer. Para a sátira, essas são virtudes indispensáveis, que as personagens herdam, em particular, de Sócrates, dos heróis da comédia, como Trigeu e Diceópolis, bem como dos filósofos cínicos: mas o resultado é algo de novo, que define a figura do herói satírico. A essas virtudes, une-se o riso, que, como uma marca, cumpre a ação da sátira.

PALAVRAS-CHAVE: Luciano de Samósata; sátira; herói satírico; liberdade de palavra; riso.
\end{abstract}

\section{Satira ed eroi altri}

Venippo di Gadara è una figura particolare della tradizione filosofica e letteraria, del quale però non sappiamo molto. Ma in Luciano il filosofo cinico diviene il protagonista della satira, in particolare dell'Icaromenippo e della Negromanzia, opere nelle quali assume il ruolo e le caratteristiche di un eroe, o meglio di quello che chiamiamo eroe satirico. ${ }^{1}$ Traendo lo

\footnotetext{
^alcam@unive.it

${ }^{1}$ Riprendo qui in parte, ma con alcuni approfondimenti e nuovi sviluppi significativi, la trattazione che ho proposto per il saggio introduttivo all'Icaromenippo o l'uomo sopra le nuvole (Alessandria: Edizioni dell'Orso, 2009). Come work in progress le cose qui dette costituiscono anche la preparazione a un lavoro più ampio e sistematico sulla
} 
spunto da ciò che avviene in queste due opere, proviamo qui a definire le caratteristiche costitutive di questo personaggio che possono valere anche per gli altri eroi della satira - come pure per l'autore -, a partire sempre dal riferimento primo della Commedia e dalle categorie che valgono per l'eroe comico. ${ }^{2} \mathrm{E}$ a queste si fondono fino a divenire paradigma prevalente le qualità e i modi dei Cinici, ${ }^{3}$ dei quali Menippo è il rappresentante più presente e più significativo nelle strategie letterarie e satiriche di Luciano. ${ }^{4}$

L'eroe satirico è per natura un eroe altro, proprio per le specifiche dinamiche della satira che ha come obiettivo essenziale l'osservazione critica. Ossia questo eroe tutto particolare deve essere diverso dagli uomini della realtà - cioè rispetto ai parametri dell'opinione comune e delle convenzioni sociali - per trovare quella distanza che è indispensabile se si vuole guardare la realtà stessa per smascherarne le contraddizioni e i vizi. ${ }^{5}$ Ma se questo personaggio si mette a fare l'eroe, risulta diverso anche dagli eroi del mito e della tradizione poetica dei quali sembra seguire le tracce nelle sue imprese. Egli è un po' un uomo qualunque, un po' un eroe vero e proprio in una commistione strana e

voce satirica che dall'incontro lucianeo di Ouro Preto ha tratto motivi di riflessione e di incoraggiamento (Gli occhi e la lingua della satira. Studi sull'eroe satirico in Luciano di Samosata, 2013).

${ }^{2}$ Per una definizione delle caratteristiche specifiche dell'eroe comico, del quale i protagonisti della satira lucianea sono per molti aspetti gli eredi, cf. Camerotto, op . cit., 2007 (con la bibliografia). A questo proposito va ricordato in particolare lo studio di Whitman, op. cit.

${ }^{3}$ Gli eroi satirici di Luciano, in genere porte-parole oppure alias dell'autore, molto spesso pur adottando categorie o atteggiamenti dei Cinici, sono altro dai Cinici stessi. E talvolta Luciano è fortemente critico nei confronti dei filosofi cinici.

${ }^{4}$ Cf. in particolare l'indicazione programmatica di Bis acc. 33. Menippo compare ripetutamente da protagonista dell'osservazione satirica nei Dialoghi dei morti, cf. Relihan, op. cit., 1987, p. 190-204.

${ }^{5}$ Così appare Menippo di ritorno dai suoi viaggi fantastici e satirici agli occhi e agli orecchi del suo interlocutore nel dialogo, ossia strano e diverso: l'esperienza satirica ne ha cambiato le categorie (Icar. 1, Nec. 1 ss.). In maniera analoga Luciano mette in scena un personaggio, un suo porte-parole, che è appena ritornato dal viaggio a Roma

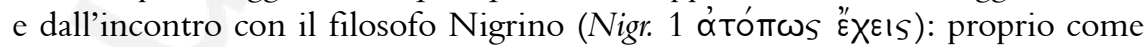

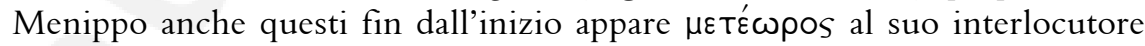
(Nigr. 1, 5). La diversità - sia interiore sia esteriore - come virtù del filosofo cinico è

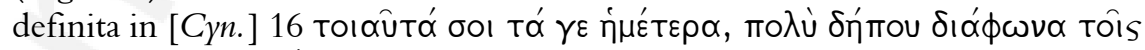

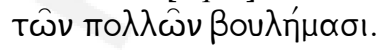


inestricabile che gli permette di svolgere il suo ruolo. Arriva anche a essere per vie poetiche e paradossali un dio e addirittura sa trasformarsi e assumere la natura di un animale e di altro ancora. ${ }^{6} \mathrm{E}$ in questo sicuramente è vicino più che mai alle figure degli eroi comici di Aristofane e della Commedia antica.

Se in principio il Menippo lucianeo è un comune mortale, una figura di tutti i giorni, come un Trigeo, un Diceopoli o una Lisistrata, da questo punto di vista non è semplicemente uno tra gli altri, perché reca con sé i segni di una alterità e di una marginalità che è voluta e necessaria e inoltre appare dotato di caratteristiche aberranti e paradossali: insomma vi sono gli elementi di uno xenon che appare programmatico. Le radici sono complesse e sono delineate nel manifesto della mixis lucianea di Bis acc. 33. ${ }^{7}$ Oltre al modello già composito della commedia, si intrecciano qui nella figura del personaggio satirico almeno due altri fattori, i paradigmi filosofici del kynikos tropos, e con essi anche i tratti seriocomici e per certi versi ambigui che sono propri dell'immagine di Socrate.

Quello che va messo in luce sono le "virtù" dell'eroe satirico, che stanno tutte in funzione dell'obiettivo, la satira. Sono virtù dell'essere, che spiegano qual è la natura di questo eroe altro. Sono poi, per le imprese straordinarie che egli deve compiere, virtù del fare. E se la satira è prima di tutto un'osservazione straniante, il nostro eroe ha bisogno di speciali virtù del vedere. Infine viene il dire: ossia la satira nella sua concreta manifestazione è fatta di parole, che possono essere attacco diretto e descrizione straniante oppure narrazione di un'avventura satirica che contiene l'attacco e la critica. Anche per questo l'eroe satirico ha bisogno di virtù particolari. E oltre le parole viene il riso, che è effetto finale e via breve alla satira.

\section{Le virtù dell'essere}

\section{II.1. Un uomo qualunque al di fuori delle regole}

In questo quadro generale delle virtù satiriche si può cominciare già dall'aspetto: quello del nostro personaggio sarà il contrario - è ovvio

\footnotetext{
${ }^{6}$ In Camerotto, op. cit., 1998, p. 199-218, l'attenzione su questi aspetti è rivolta a definire lo spostamento del punto di osservazione.

${ }^{7}$ Cf. Camerotto, op. cit., 2009a, p. 1-8.

${ }^{8}$ Su questi tratti dell'immagine di Socrate cf. Lanza, op. cit., p. 65-89.
} 
- di ciò che ci si attende per un eroe. Nel caso di Menippo come di altri protagonisti lucianei è la figura di un vecchio, che di certo non si distingue per bellezza con la sua testa pelata ${ }^{9}$ e che va in giro con addosso il suo logoro mantello coperto di toppe. ${ }^{10}$ Si innesca - direi a prima vista - un rovesciamento delle attese che denunzia una funzione.

Ma continuiamo. Anticipando una valutazione che ha a che fare anche con la condizione sociale del personaggio, questi appare povero di una povertà assoluta, tanto che non sa neppure se l'obolo sia tondo o quadrato, ${ }^{11}$ ed è uso a fare - si potrebbe dire per professione paradossale - il mendico. ${ }^{12}$

${ }^{9}$ In Icar. 2 v'è l'ironia sulla “avvenenza” di Menippo attraverso il paragone con

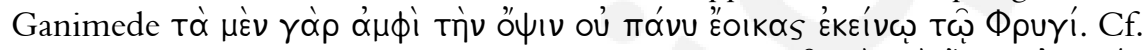

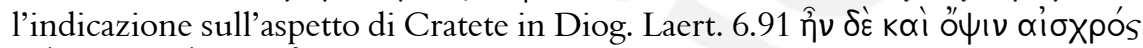

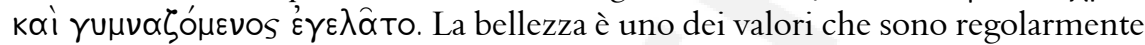
bersaglio della satira lucianea. Per il motivo della vanità della bellezza cf. Nec. 15, D. mort. 1 (1) 3, 5 (18), 20 (10) 3, 29 (24) 2. Per la critica cinica della bellezza cf. Diog. Laert. 6.9 (Antistene), 6.96 (Cratete). La bellezza è uno dei beni terreni di cui è necessario spogliarsi in Pl. Gorg. 523c.

${ }^{10}$ Per l'aspetto sordido del filosofo cinico e la sua vita da miserabile cf. Vit. Auct. 7-9. L'immagine ritorna da altra prospettiva in Icar. 31. Sulla "divisa" dei Cinici cf. Desmond, op. cit., p. 78-82.

${ }^{11}$ La $\pi \varepsilon v i ́ \alpha$, la povertà, è rifiuto dei beni materiali e delle ricchezze quale principio etico vissuto di persona e ostentato come critica sociale: D. mort. 2 (22) 1 Menippo non possiede nemmeno un obolo, Cat. 15 (il catalogo dei beni che Micillo il ciabattino

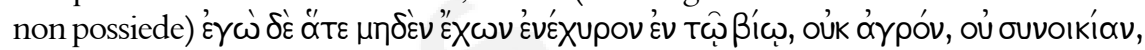

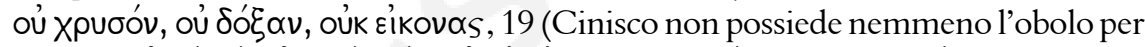

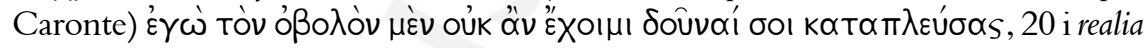
della povertà del ciabattino Micillo, 21 (Micillo non sa neppure se l'obolo che

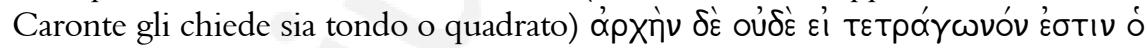

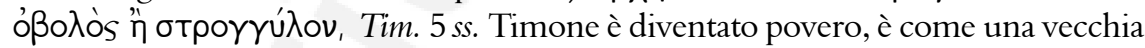
stele rovesciata, e zappa la terra, Gall. 1 Micillo, che è povero, può essere ricco solo in sogno, ma dopo l'osservazione satirica rinuncia a ogni desiderio di ricchezza e a essa preferisce la fame (Gall. 33), [Cyn.] 16 l'aspetto e la condizione di pauper è posta in contrapposizione a quella di tutti gli altri. Per l'elogio della povertà cf. Nigr. 12-14, Fug. 24. Sulla povertà come rovesciamento e quindi spostamento del punto di osservazione, come principio per la satira e la parodia, cf. Lichacëv, op. cit., p. 336 ss.

${ }^{12}$ Per l'immagine del filosofo cinico come mendico cf. Luc. Fug. 14, 17, Pisc. 35

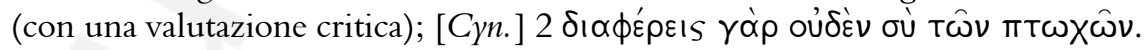
Attorno alla figura di Diogene che fa il mendico cf. Diog. Laert. 6.26, 49, 56, 57, 59,

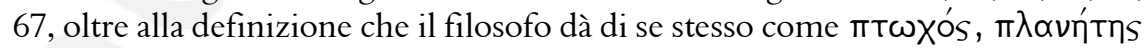
(6.38). La "professione" di mendico vale anche per Menippo, Diog. Laert. 6.99

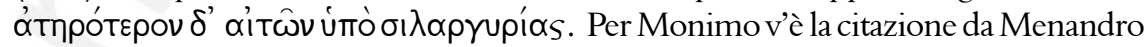

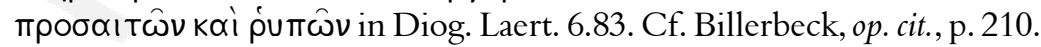


Ma la povertà, la $\pi \varepsilon v i ́ \alpha$ che spesso contraddistingue l'eroe satirico, si connette a una scelta fondamentale per la ricerca della verità, $\alpha^{\prime} \lambda \eta^{\prime} \theta \varepsilon ı \alpha$, ed è garanzia imprescindibile delle virtù di cui parleremo, dell' ' $\varepsilon \lambda \varepsilon u \theta \varepsilon \rho i ́ \alpha$ e in particolare della $\pi \alpha \rho \rho \eta \sigma i \alpha .{ }^{13}$

Gli attributi esteriori sono quelli del filosofo cinico, ai quali si accompagna l'appellativo marginale e provocatorio di "cane": ${ }^{14}$ ma tutti questi elementi che contraddistiguono il nostro eroe satirico sono già fattori specifici della satira. E difatti hanno il valore di una carta d'identità o piuttosto di un identikit per Menippo, come avviene nel primo dei Dialoghi dei morti: nella missione che dall'Ade Diogene affida a Polluce, quando questi secondo il proprio mito risalirà sulla terra non avrà nessuna difficoltà a riconoscere Menippo. Basteranno per l'appunto i pochi tratti ben caratterizzati della sua immagine, ${ }^{15}$ e a queste indicazioni si aggiungono le specifiche azioni della satira:

${ }^{13}$ La povertà è categoria specifica dell'eroe satirico, e prima ancora naturalmente del filosofo cinico, cf. p. es. Diog. Laert. 6.87 (a proposito di Cratete). Dalla scelta

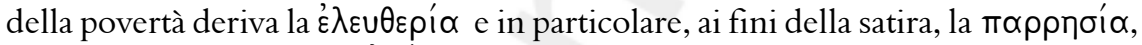
che avra come oggetto l'á̉ $\eta^{\prime} \theta \varepsilon ı$ ma che è comunemente percepita in termini negativi o con timore: cf. Vit. Auct. 10 iт $\alpha \mu$ òv xp

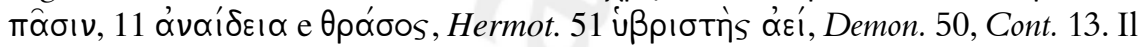

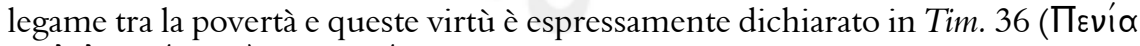

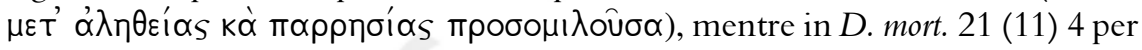
Cratete e Diogene l'unica vera ricchezza, che al contrario dell'oro si può portare

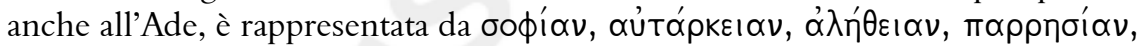

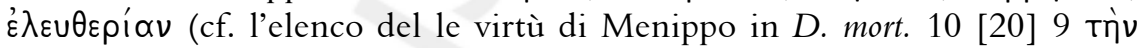

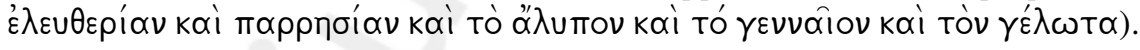
Sulla parrhesia cf. infra § V.

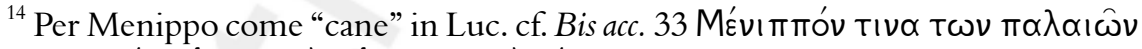

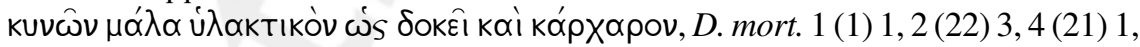
Vit. Auct. 7 (a proposito di Diogene), 10 (i modi aggressivi del cane). Secondo la notizia di Diog. Laert. 6.13, Antistene era solito discorrere presso il ginnasio di Cinosarge e da questo deriverebbe il nome, e lo stesso Antistene era chiamato 'A

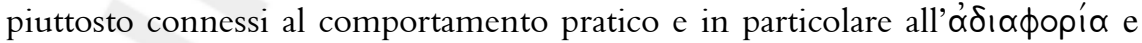

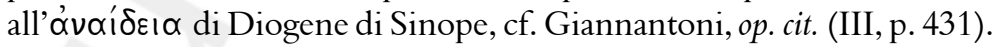

${ }^{15}$ Cf. l'immagine di Menippo con bisaccia, bastone, mantello in D. mort. 20 (10) 2. Il paradigma è quello del cinico Diogene (Diog. Laert. 6.22 ss., cf. 6.13 per Antistene), al quale sembra qui sovrapporsi Menippo nel ritratto (cf. Hall, op. cit., p. 79). Sull'immagine dei filosofi cinici cf. Giannantoni, op. cit. (IV, p. 499-505). Si può confrontare l'immagine lucianea (e comunque tradizionale) di Socrate, che si contraddistingue per la testa

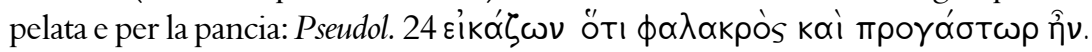




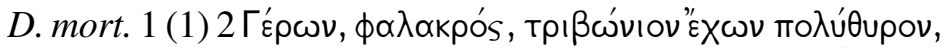

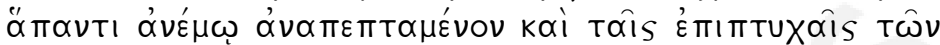

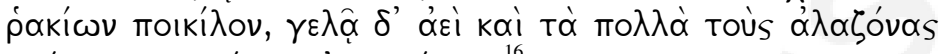

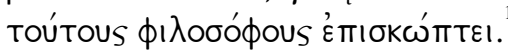

Sulla funzione dell'aspetto esteriore dei Cinici è significativo quanto dice R. Bracht Branham, il quale sulle tracce di M. Bachtin sottolinea come "Diogenes made of himself 'an object of experimentation and representation'" e osserva come l'immagine e insieme ad essa il corpo rappresentino uno strumento a tutto campo per la prassi e la comunicazione filosofica dei Cinici:

the body is not just a tool for attacking enemies or shocking the public - though it serves both these eminently rhetorical purposes it is also a source of the Cynic's authority, his warrant for engaging in parrhesia. He uses it as the visible expression of his exemption from social control, of his immunity to doxa or public opinion: it confers on his conduct the sanction of nature. ${ }^{17}$

Approfondiamo ora il ritratto sul piano sociale. Leroe satirico appare - sempre secondo i modi di vita dei Cinici - come un estraneo alla società, che sfugge alle regole e non si assoggetta alle convenzioni, al potere e alle ricchezze, le quali anzi divengono regolarmente il bersaglio dei suoi attacchi. ${ }^{18}$ Non ha polis e perfino non possiede una casa, ${ }^{19}$ né ha vincoli familiari, rifiuta il matrimonio e la procreazione dei figli. ${ }^{20}$ Una definizione

16 "È vecchio, calvo, ha un mantellaccio pieno di buchi, aperto a tutti i venti, variopinto di toppe. Ride sempre e per lo più canzona quei fanfaroni dei filosofi". ${ }^{17}$ Cf. Branham, op. cit., 1994, p. 335 e 351.

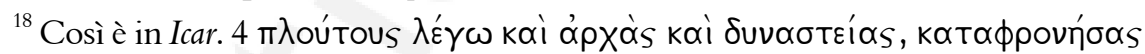
$\alpha u ̛ \tau \omega \hat{v}$. Parallelamente il disprezzo dei beni riconosciuti dalle convenzioni sociali e delle relative ambizioni umane è alla base anche dell'impresa della Negromanzia (Nec.

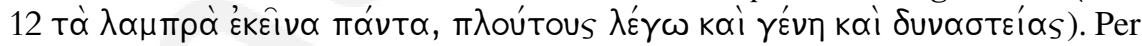
questa sequenza topica dei beni desiderati da tutti cf. Merc. cond. 27, Alex. 14, Tox. 45, Hermot. 7, 71.

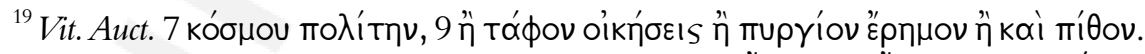

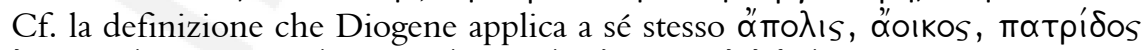

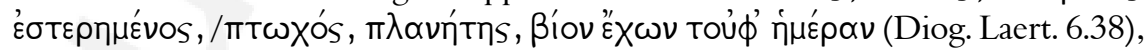
la quale contiene anche una identificazione eroica (cf. Branham, op. cit., 1994, p. 340). Sul pithos di Diogene cf. Diog. Laert. 6.23, Dio Chrys. Or. 6.1-3. Sul cosmopolitismo dei Cinici cf. Moles, op. cit.

${ }^{20}$ Cf. Diog. Laert. 6.72. Per il rifiuto del matrimonio cf. anche Epict. Diss. 3.22.76. 
di queste categorie che possono apparire estreme e che trovano variamente applicazione per l'eroe satirico è nel paradigma del filosofo cinico illustrato da Epitteto:

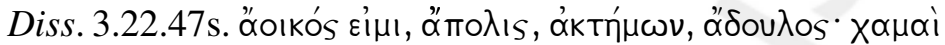

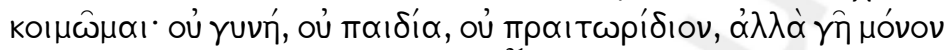

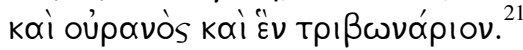

E lo stesso Luciano ne dà una definizione che riunisce gli aspetti più significativi del bios cinico in Vit. Auct. 9:

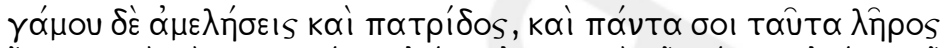

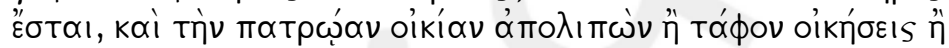

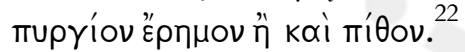

Arrivare a tali estremi cinici non è sempre necessario, e a volte Luciano polemizza con questa spettacolarizzazione della filosofia, ${ }^{23}$ mentre sembrerebbe preferire per esempio la diaita più mite e più sociale di un filosofo come Demonatte, idealizzato in un ritratto encomiastico. Questi mantiene le specifiche virtù ciniche e soprattutto satiriche (Demon. 3 ö $\lambda$ ov

${ }^{21}$ "Senza casa, senza città, senza proprietà, senza schiavi, dormo per terra. Non ho una moglie, non ho figli, non un luogo dove stare, ma per me v'è solamente la terra e il cielo e un mantelletto". Anche nella rappresentazione di Diogene proposta da Massimo di Tiro il filosofo cinico è libero da ogni condizionamento e vincolo. Il testo riporta l'intera gamma delle cose alle quali ci si deve sottrarre per la libertà: Max. Tyr. Or.

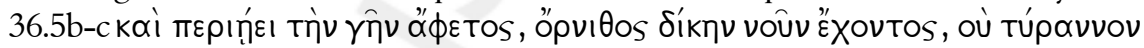

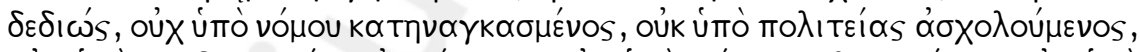

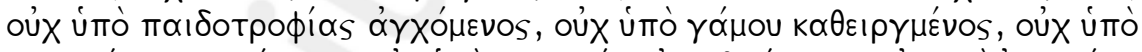

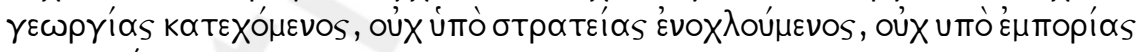
пєріфєрó $\mu \varepsilon v o s$. Le cose di cui gli uomini si occupano con grande serieta e a cui danno grande importanza non sono altro che un gioco da bambini del quale non si può che

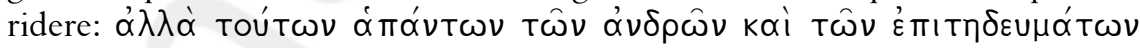

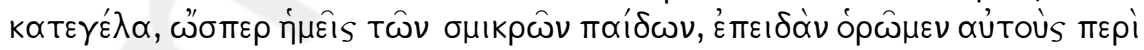

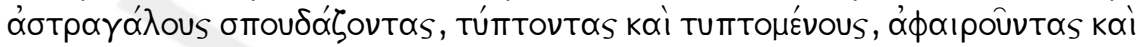
åфaıpounévous.

22 "Non ti curerai più di moglie, figli e patria, che per te saranno tutte parole vuote, e, lasciata la casa paterna, andrai ad abitare un sepolcro, una torre abbandonata o anche una botte".

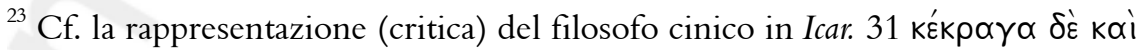

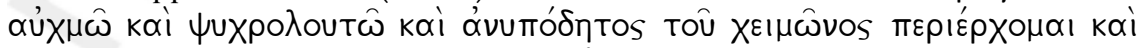

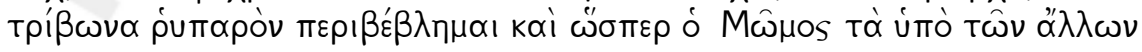

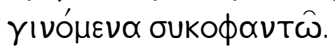




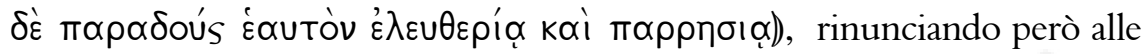
manifestazioni più ostentate e problematiche per adottare modi vicini a quelli di tutti: $:^{24}$

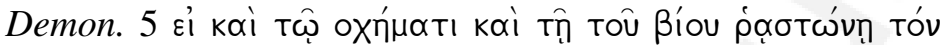

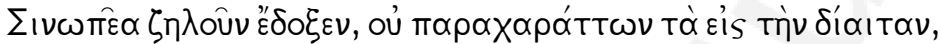

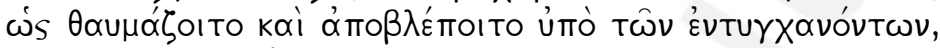

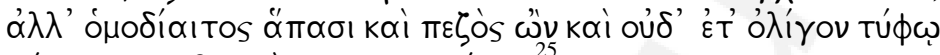

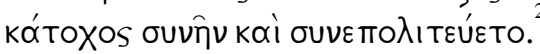

Ma anche in Luciano non manca la ricerca dell'ultima apanthropia quale unica via per rispondere ai mali della vita umana come avviene nel caso di Timone. ${ }^{26}$

\section{II.2. Uno straniero}

Nella ricerca dello straniamento l'eroe satirico può presentarsi come uno straniero, ${ }^{27}$ che proviene da lontano e da un mondo diverso.

${ }^{24}$ Questa prospettiva riporta anche alle strategie letterarie della satira lucianea, Bis acc.

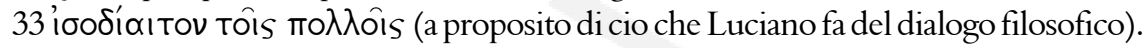

25 "Anche se poté sembrare per l'aspetto e per la trasandatezza della vita che imitasse il Sinopeo, non alterava il suo modo di vivere per essere ammirato e guardato da chi lo incontrava, ma in questo era come tutti, uno dei tanti, e stava tra la gente e accettava gli impegni politici, mai vinto, neppure un momento dalla superbia”.

${ }^{26} \mathrm{Il}$ personaggio satirico si presenta come un estraneo o un emarginato nella società che è oggetto della sua critica. Paradigmatica è la solitudine di Timone nell'opera satirica che dal protagonista prende il nome. Timone, che odia dei e uomini, si

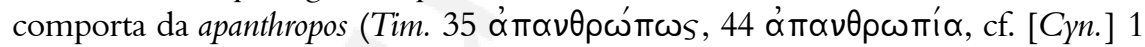

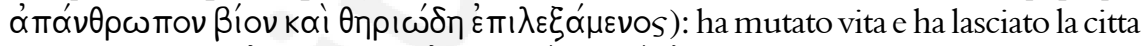

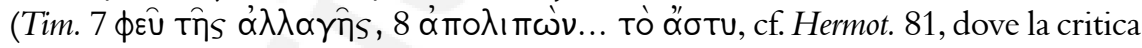
proviene da uno che abita in campagna). Si pone al di fuori della comunità sociale: non esiste più per lui nessun tipo di istituzione sociale (43); la sua vita è come quella dei lupi e vuole starsene solo (42). Cf. Hist. conscr. 3: Diogene, che diviene il modello di comportamento per la critica storiografica di Luciano, è l'emarginato nella città di Corinto. Su questa prospettiva cf. Frye, op. cit., p. 311. Si può confrontare anche $A P$ 7.313, dove Timone dalla tomba rifiuta pure il valore (e il vincolo) immancabile dell'identità.

${ }^{27}$ Si veda l'esempio di Caronte, che sale dagli Inferi pronto a osservare da straniero

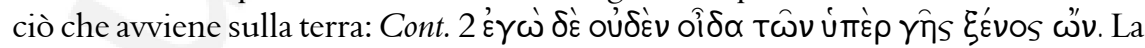
funzione delle categorie satiriche che sono proprie dello straniero è ben sottolineata da Saïd, op. cit., p. 164 "il [Luciano] se sert de son héros [lo scita Anacarsi] pour mettre la Grèce a distance et forcer son lecteur à porter un regard neuf, donc critique, sur les réalités qui lui sont le plus familières". 
Nell'Icaromenippo questo aspetto, nel senso di una origine e di una provenienza diversa sul piano etnico, geografico e culturale, non è particolarmente evidenziato, anche se possiamo riconoscere questa funzione in due indicazioni, proprio all'inizio del testo, relative al modo di esprimersi di Menippo e alle cose che dice: l'amico che lo ascolta nelle sue elucubrazioni lo sente usare parole straniere e lo paragona ai Fenici. ${ }^{28}$ E così vale in altri termini per la Negromanzia. ${ }^{29}$

Ma non va dimenticato in questa prospettiva il fatto fondamentale dei due testi che narrano pur sempre di un viaggio. Menippo giunge da un altrove e ne ha adottato le caratteristiche, le quali ovviamente non possono che essere paradossali. E questo altrove non è un qualsiasi paese straniero con le sue particolarità erodotee, ma è l'altrove per definizione, il cielo degli dei e l'Aldilà dei morti. ${ }^{30}$ Se nell'Icaromenippo il linguaggio diviene aereo, nella Negromanzia le parole giungono direttamente dalla voce dei morti, o meglio di Euripide e di Omero che Menippo ha incontrato. ${ }^{31}$

Per avere una percezione della funzione straniante e satirica di questi fatti si può confrontare l'immagine dello stesso Menippo, così come è rappresentata da una voce della Suda. ${ }^{32}$ Il filosofo cinico per la sua azione satirica si presenta in maniera teatrale - o per meglio dire

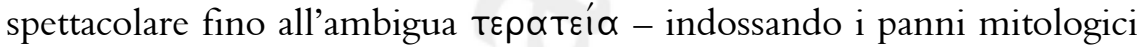

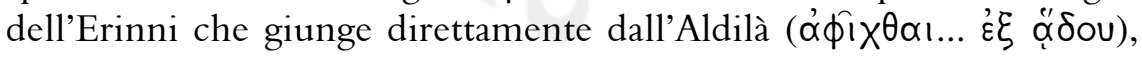
insieme a una serie di attributi vari a partire dalla veste del mago fino al pilos e al bastone. Il suo ruolo è quello di દ̇ті́бкотоS che - nella direzione opposta di quanto fa nella Negromanzia ma con funzione uguale dall'Ade risale sulla terra, con la missione di osservare e mettere a nudo i vizi degli uomini:

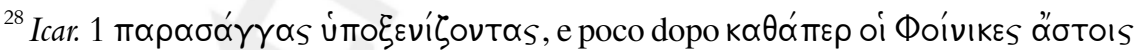

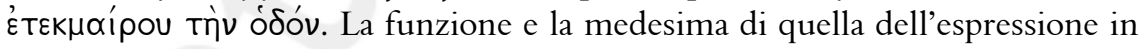
versi in Nec. 1 ss. a marcare fin dall'inizio l'alterità del personaggio e della sua logica.

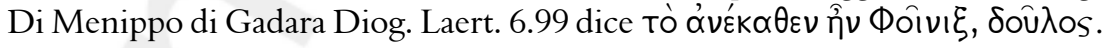

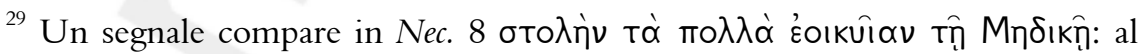
complicato equipaggiamento mitologico di Menippo si aggiungono anche la veste e i caratteri orientali della sua guida, il mago caldeo Mitrobarzane, al quale si adegua per giungere nell'Aldilà.

${ }^{30}$ Menippo giunge dall'Aldilà anche nelle stesse opere di Luciano anche dal punto di vista compositivo, dissotterrato dalla tomba (Bis acc. 33) o redivivo (Pisc. 26).

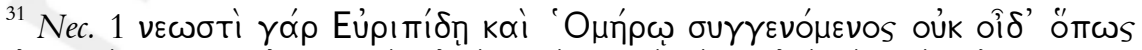

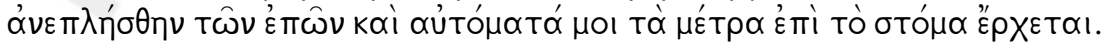

${ }^{32}$ Suda ö 180, s.v. фorı́s.
} 


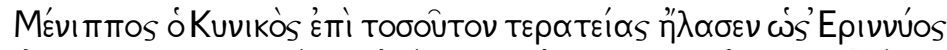

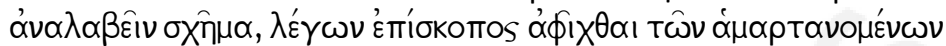

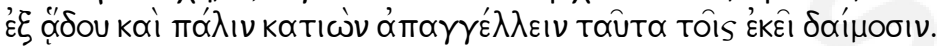

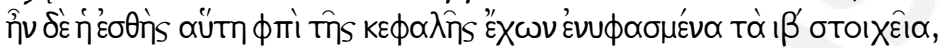

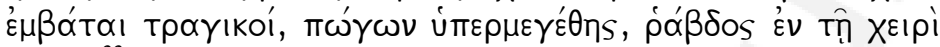
$\mu \varepsilon \lambda^{\prime}$ ivๆ. ${ }^{33}$

Così, se nell'Icaromenippo l'eroe satirico arriva diretto dalle sedi di

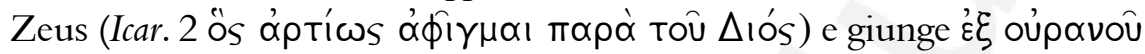
da vero e proprio $\delta ı \pi \varepsilon \tau n ́ s,{ }^{34}$ si può ricordare che, nell'idealizzazione della figura di Diogene, il filosofo cinico viene definito "cane celeste" e si gioca sul suo nome che reca il significato di "stirpe di Zeus" come avviene

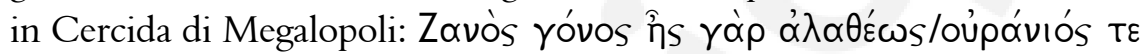
kú $\omega \nu .{ }^{35}$ Si può anche ricordare che da Epitteto sempre Diogene è definito in maniera conseguente come un messaggero celeste: ă $\gamma \gamma \varepsilon \lambda$ os ámò toû $\Delta$ Iòs åm

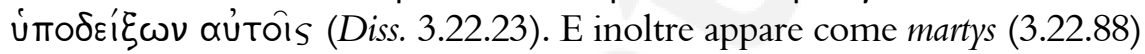
e come kataskopos, il quale annunzia la verità senza lasciarsi turbare dalla

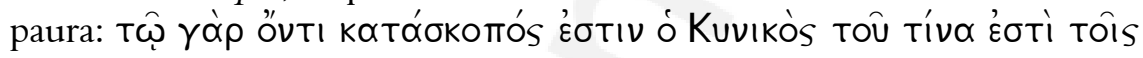

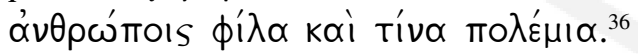

Ma la specifica dimensione dello straniero ha grande importanza nelle strategie satiriche di Luciano, che per la sua nascita sulle rive dell'Eufrate e per la lingua materna è in primis egli stesso uno straniero

\footnotetext{
33 "Menippo il cinico si spinse a un tal punto di ciarlataneria da indossare i panni di una Erinni, dicendo di essere giunto dall'Ade come ispettore delle colpe per scendere poi di nuovo giù a riferirle ai demoni di là. La sua veste era siffatta, un chitone scuro lungo fino ai piedi, attorno a questo una fascia di porpora, un pilleo arcade sulla testa con ricamati i dodici segni zodiacali, coturni da tragedia, una barba lunghissima, un bastone di frassino in mano". Sul passo cf. Relihan, op. cit., 1987, p. 193 ss. La medesima immagine è proposta in Diog. Laert. 6.102 per Menedemo. Sulla relazione tra Menippo e il mondo dei morti cf. Relihan, op. cit., 1990; 1996, p. 275.

${ }^{34}$ Cf. Camerotto, op. cit., 2009 a, p. 98.

${ }^{35}$ Cercidas fr. 1.7-8 Powell. Analogamente avviene in AP 7.64.4, 11.158.6 (cf. anche ps.-Diogenes Epist. 7.1).

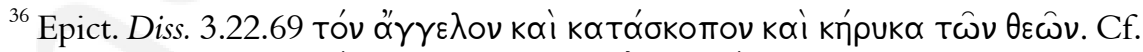

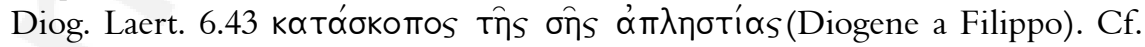
Billerbeck, op. cit., p. 206 ss.
} 
nel mondo greco-romano. ${ }^{37}$ Lo straniero può essere proprio colui che ha una $\gamma v \omega ́ \mu \eta$ ò $\theta \dot{\eta}$ in rapporto all'Aletheia (Pisc. 19). La dimensione di xenos funziona già sul piano della composizione letteraria. ${ }^{38} \mathrm{Ma}$ soprattutto va considerato che l'osservazione della realtà da parte di uno straniero rappresenta un radicale rovesciamento di prospettiva, perché da estraneo può essere l'unico in grado di smascherare gli inganni consolidati di una opinione comune chiusa e di convenzioni sociali irrigidite dalle abitudini. È questo in effetti che avviene nell'Anacarsi, nello Scita e nel Tossari o nel caso paradigmatico dello straniero che tra i Cumani terrorizzati smaschera l'asino travestito da leone (Pisc. 32, cf. Fug. 13, Pseudol. 3): è così il mondo greco che appare strano (Anach. 6

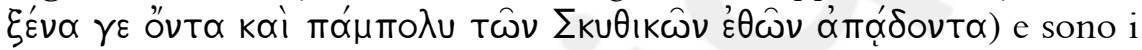

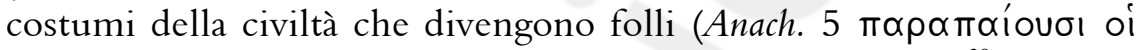

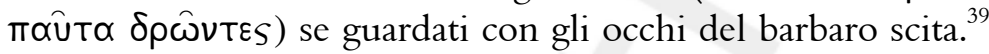

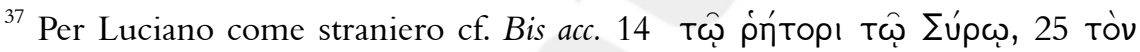

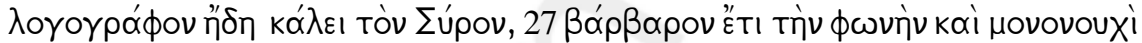

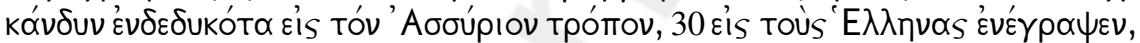

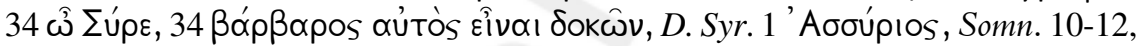

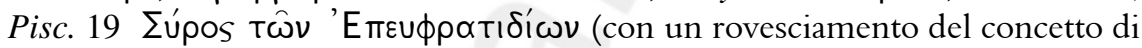

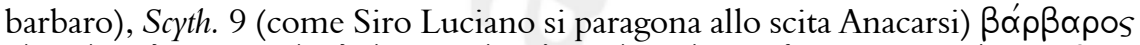

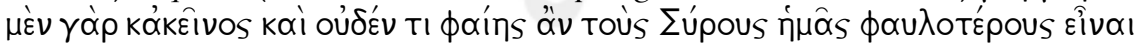
$\tau \hat{\omega} v \sum \mathrm{k} \cup \hat{\omega} v$, Hist. conscr. 24, Ind. 19. Per la lingua barbara di Luciano cf. Pisc. 19, Bis acc. 27, Ind. 4, (Somn. 8), e per contro l'elogio dell'origine e della lingua in Imag. 15. La lingua barbara è tra le raccomandazioni di Diogene per l'attacco satirico: Vit.

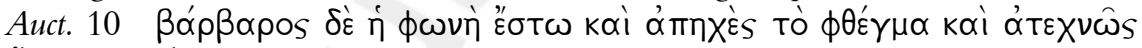
ömoıv kuví. Cf. Jones, op. cit., p. 6-10. Cf. anche la definizione di Dioniso come ¿upoфoívikos (Deor. conc. 4), da associare a ciò che il dio fa in Bacch. 1 ss. come ipostasi della composizione lucianea, e a margine la rappresentazione di Mitra in

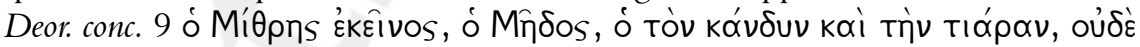

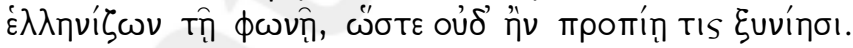

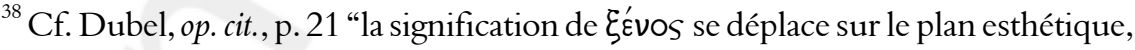
du sens d'étranger à celui d'étrange et de nouveau. (...) la qualité de barbare du personnage devient une qualité créatrice".

${ }^{39}$ Nell'Anacarsi, lo straniero scita è la persona satirica che critica i costumi tradizionali sulla base dei quali i Greci si contrappongono ai barbari:Anach. 6 estraneità dei costumi dei Greci per gli Sciti e viceversa; 14 Anacarsi compie un lungo viaggio per osservare i costumi dei Greci; 17 dallo straniero e barbaro si può imparare e per questo egli deve

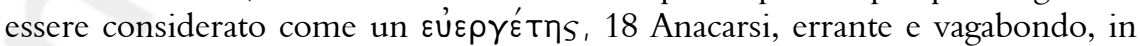
contrapposizione agli Ateniesi autoctoni che abitano da sempre l'Attica. Cf. Bernardini, op. cit., 1991, p. 176, p. 178; 1992, p. 46; 1995, p. 15. Altri esempi: Bis acc. 9-12 Pan, un meteco (9), un arcade ad Atene (11), come osservatore satirico; Nigr. 2 Nigrino straniero 
Queste forme di estraneità e di marginalità fanno dell'eroe satirico un essere solo e isolato alla maniera dei grandi eroi del mito: il nostro eroe è pronto così a battersi contro le opinioni di tutti fino all'ostilità dichiarata delle parole e delle azioni. Nella sua eleutheria non dipende da niente e da nessuno, per diventare protagonista unico dell'impresa, dell'osservazione e dell'attacco satirico. ${ }^{40}$

\section{II.3. Fare l'eroe}

Ma c'è dell'altro, in particolare quando vengono inscenate azioni fantastiche. Questo strano ometto deve fare l'eroe: nella sua impresa paradossale indossa letteralmente i panni degli eroi veri, e non gli bastano nemmeno quelli di uno solo, perché se contamina la dimensione dell'uomo qualunque con la natura e le gesta eroiche, il suo programma è proprio la mixis, la molteplicità delle componenti che gli garantisce il successo nell'impresa. È quello che avviene in maniera potremmo ben dire teatrale per il Menippo della Negromanzia, il quale per scendere all'Ade - unica via che permette di comprendere realmente qual è il modo migliore per vivere sulla terra - deve recitare la parte dell'Eracle tragico, e insieme di Orfeo e di Odisseo, ossia si prende le virtù e le risorse degli eroi che l'hanno preceduto nell'impresa impossibile della catabasi con andata e ritorno. Armato di leonte, di lira e di pilleo si fa passare di volta in volta per l'uno o per l'altro eroe (Nec. 1, 8, 10),

a Roma; Pisc. 38 gli abitanti di Ilio che si fanno rappresentare le loro sventure da un attore straniero (cf. Pseudol. 10). La medesima prospettiva può avere altre applicazioni,

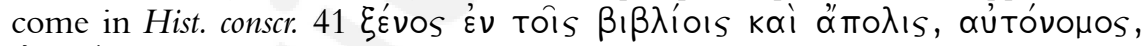
$\alpha \beta \alpha \sigma i ́ \lambda \varepsilon \cup$ Tos : l'autore storico - come quello satirico - deve essere estraneo a qualsiasi realta, addirittura straniero nei suoi stessi libri. Come osserva Relihan, op. cit., 1996, p. 272 nella figura di Menippo e tra i Cinici il principio dell'estraneità funziona anche in relazione alla stessa "scuola" filosofica: "Menippus may prove his Cynicism, in effect, by laughing at Cynic certainties". Ricordiamo che in Pisc. 26 Menippo è il

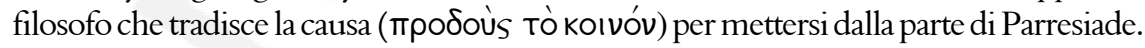
${ }^{40}$ La contrapposizione con le convenzioni sociali è una disposizione programmatica e ostentata che segue sempre i paradigmi cinici. Cf. i tratti che contraddistinguono

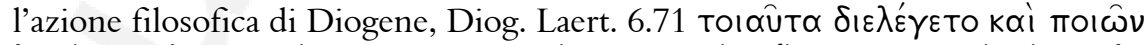

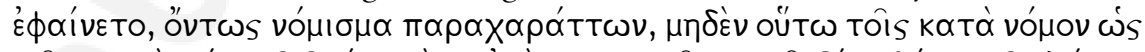

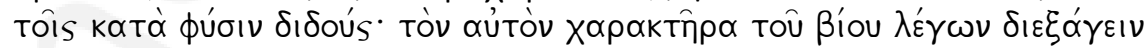

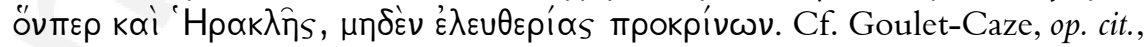
p. 195-222. 
migliorando addirittura la performance da eroe comico di Dioniso/ Xantia nelle Rane di Aristofane. ${ }^{41}$

Nell'Icaromenippo la dimensione eroica si rivela negli attributi, nei paragoni e nelle azioni. Se appare ironico il confronto con Ganimede da parte dell'interlocutore che ascolta il racconto incredibile dell'ascesa alle sedi degli dei, il paragone assurdo ha comunque il suo peso perché il paradosso nell'impresa satirica diviene realtà. E difatti se Menippo non ha la bellezza di Ganimede - e per l'avvenenza come abbiamo detto può piuttosto apparire come il suo opposto - sarà proprio il bel fanciullo frigio che gli farà da coppiere nel simposio degli dei e che gli riserverà un favore speciale: e come vedremo subito, non sarà cosa priva di implicazioni. Ma la dimensione eroica Menippo se la conquista prima di tutto nell'azione, diventa un Dedalo per escogitare il sophisma che lo porta su in cielo, ${ }^{42}$ e anzi

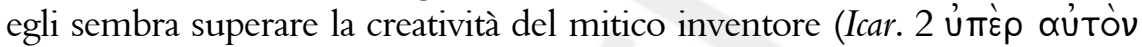
$\Delta \alpha(\delta \alpha \lambda \circ v)$. Ma al tempo stesso, nella prospettiva autoironica della satira che genera anche il titolo del racconto, è pure e soprattutto un novello Icaro, il quale nella paventata caduta darà il nome all'eroico mare Menippeo. ${ }^{43}$ E nel momento più importante dell'osservazione satirica per poter vedere tutte le cose e le azioni degli uomini anche nei minimi dettagli non manca il paragone con le risorse di un Linceo. ${ }^{44}$ L'arrivo in cielo, poi, lo pone alla pari - o meglio anche in questo caso al di sopra - di Oto e di Efialte agli occhi degli stessi dèi preoccupati e riuniti in assemblea proprio per questa audacia dell'eroe satirico. ${ }^{45}$ V'è anche un sorriso di Zeus, quando

${ }^{41}$ In proposito cf. Habash, op. cit., p. 2-5.

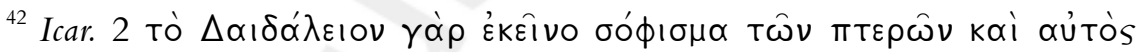

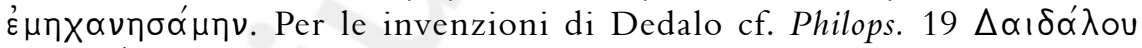

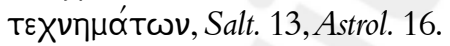

${ }^{43}$ Icar. 3. Cf. l'uso satirico del paragone con Icaro in Nav. 46 (per chi sogna di volare), Gall. 23, Astrol. 15. Il medesimo Witz del nome è riproposto in [Philopatr.] 2.

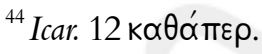

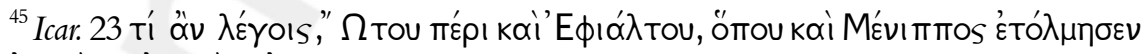

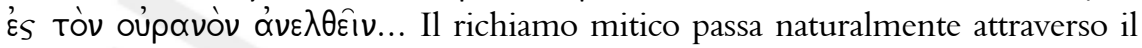
reimpiego del celebre racconto di Aristofane nel Simposio platonico, con la situazione narrativa del quale vi sono qui molti punti di contatto: gli uomini doppi muovono l'assalto al cielo, vengono paragonati alle due figure del mito con l'esplicita citazione di Omero, Zeus e gli dei si riuniscono in assemblea per decidere cosa fare di essi (Pl. Symp. 190b-c). I versi epici di Oto ed Efialte sono utilizzati in Cont. 4 da Caronte e da Hermes per la creazione della specola satirica, e i due personaggi sono attenti a disinnescare la hybris del modello. In funzione satirica il paragone è utilizzato sempre da Luciano per il maestro di retori e per la sua arroganza che lo innalza presuntuosamente al di sopra delle dimensioni di Tizio, Oto ed Efialte (Rh. Pr. 13). 
il dio mette a confronto Menippo con il pericolo epico degli Aloadi, ma il problema in concreto non è certo da meno, perché l'impresa di Menippo infrange i confini insuperabili tra l'umano e il divino, con il sigillo di quanto poi avviene nel simposio degli dei.

\section{II.4. Tra gli dei}

Infatti nella stravagante e incredibile ascesa non mancano a Menippo le qualità che rischiano addirittura di trasformarlo in un dio.

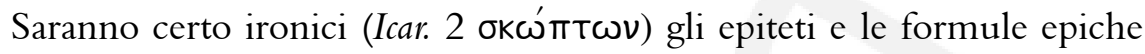
con i quali sempre l'amico si rivolge al Menippo volante, ma, come riconosce nel dialogo lo stesso interlocutore dapprima incredulo, il racconto si trasforma da narrazione fantastica in narrazione reale: ${ }^{46}$ anche l'ascoltatore prende il volo insieme al narratore. Menippo diventa così

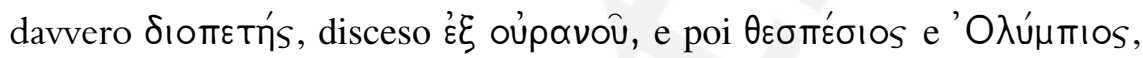
non diverso in sostanza da uno degli dei celesti di cui parla Omero con

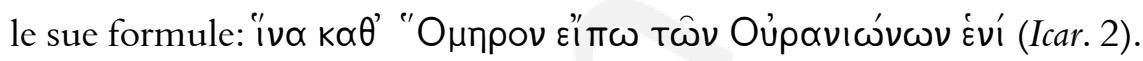
E con la vista di Linceo, Menippo fa anche quello che normalmente può fare solo lo Zeus dell'epica. Per la satira prima che la lingua sono la vista e l'udito che contano: il nostro Menippo adotta la panopsia epica di Zeus che spazia però ben oltre la potenza visiva del signore degli dei. ${ }^{47}$ Egli non rinuncia neppure ad assaggiare di nascosto il nektar che solo agli dei è riservato e che ha il potere di trasformare un mortale in un immortale. ${ }^{48}$ E poi quando ci sono da fare le considerazioni più importanti, che toccano anche le incongruenze del mondo divino, è lui e non Zeus che con una semplice metafrasi nei versi di Omero rimane desto come invece spetta al dio secondo il racconto dell'epica. ${ }^{49}$

\footnotetext{
${ }^{46}$ Questa sovversione dei piani tra pseudos e aletheia sostiene tutta la struttura narrativa delle Storie vere. Sul procedimento cf. Saïd, op. cit., p. 168 ss.

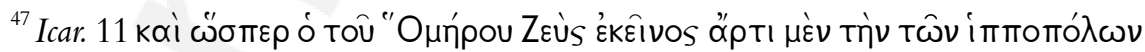

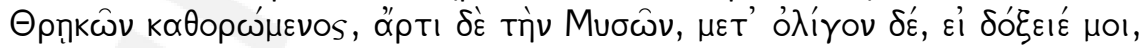

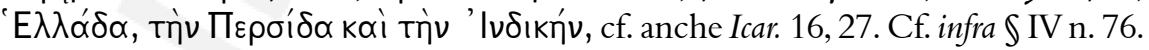
${ }^{48}$ Icar. 27. Sulla diversa dieta tra mortali e immortali (con le prospettive che si aprono per chi passa alla dieta divina) cf. p. es. quel che avviene in Hom. å 44-227: alla stessa mensa e con la ripetizione delle stesse azioni formulari ben diversa e la dieta di Hermes e di Odisseo.
}

${ }^{49}$ Icar. 28. 
Ma l'eroe satirico può essere anche un dio tra gli altri dei, così come nella Commedia, nelle Rane di Aristofane, v'è Dioniso che recita la parte dell'eroe comico: in Luciano è in genere Momo col suo nome parlante a svolgere questo ruolo. ${ }^{50}$

\section{L'impresa e le virtù del fare}

Alle qualità dell'eroe satirico corrispondono le caratteristiche dell'impresa, e perché possa essere compiuta essa richiede altre specifiche qualità. Nell'Icaromenippo ciò che l'eroe satirico compie è qualcosa di fuori dall'ordinario, è un viaggio, ossia una $\alpha_{\pi} \pi \circ \delta \eta \mu^{\prime} \alpha^{51} \mathrm{ma}$ tutta speciale, perché è un'ascesa in cielo. ${ }^{52}$ Egli fa in sostanza quello che tutti gli altri mortali non possono fare, in particolare quei filosofi che pretendono di spiegare i fenomeni celesti come se fossero stati in cielo tra gli astri. ${ }^{53}$ Menippo ci va davvero e sensibilmente, non per metafora $\mathrm{o}$ in sogno. Egli inventa una macchina per volare - che avrà grande successo in futuro - e con essa sale prima sulla luna e poi ancora più in alto oltre il sole fino alle sedi degli dei. Il volo è cosa inaudita, l'ascesa al

\footnotetext{
${ }^{50}$ Momo, figlio di Nyx (Hes. Th. 214), è la personificazione del biasimo e della critica e ben si associa ai modi del filosofo cinico (cf. l'atteggiamento di Diogene, il cui primo principio è la parrhesia [Diog. Laert. 6.69], che condivide con Momo [Deor. conc. 2, 6]). È un personaggio e un protagonista della satira in due dialoghi di Luciano, I. trag. 18-49 e Deor. conc. 1-14. Cf. anche Icar. 31, Bacch. 8, Nigr. 32, VH2.3, Iud. dear. 2, Hist. conscr. 33, Hermot. 20.

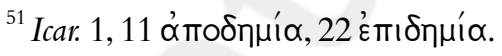

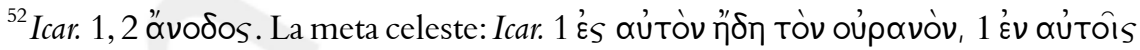

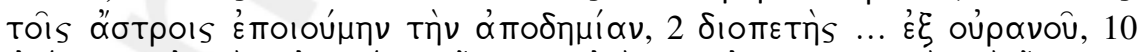

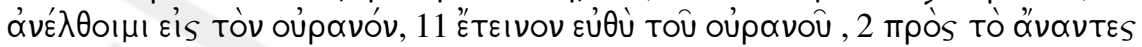

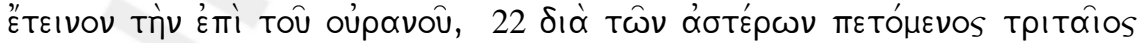

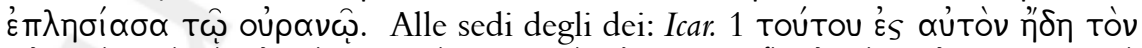

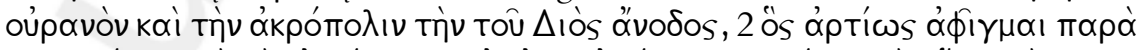

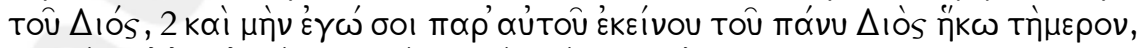

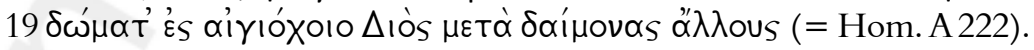

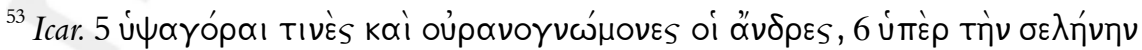

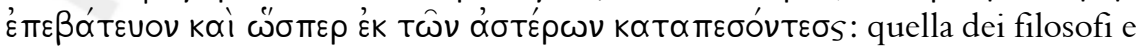
una pretesa boriosa da attaccare, mentre per Menippo il volo in cielo è una realtà.
} 
cielo è hybris. ${ }^{54}$ Nella Negromanzia agiscono le medesime categorie nella direzione opposta, a partire dal $\theta$ páбos poetico che ispira il viaggio. ${ }^{55}$

L'impresa dell'eroe satirico - secondo il lessico lucianeo - è definibile innanzitutto come una $\varepsilon$ mívoı $\alpha$, un pensiero e un progetto. ${ }^{56}$ Essa nasce sempre da un punto critico di partenza che genera un desiderio di sapere (' $\left.\dot{\prime} ı \theta u \mu i^{\prime} \alpha\right)$ e una ricerca dell' aletheia. ${ }^{57}$ Lo sprezzo delle cose umane spinge il protagonista a rivolgere gli occhi altrove, più lontano, come inizio di un percorso filosofico. ${ }^{58}$ Ma questo avvio giunge regolarmente a una aporia senza scampo (Icar. $\left.10 \alpha^{\prime} \mu \eta \chi \propto \alpha \nu \omega \nu\right),{ }^{59}$ una difficoltà

${ }^{54}$ Per il volo come fatto eccezionale, come oggetto di un desiderio impossibile, cf.
Nav. 42-44: anche se si tratta di tutt'altra cosa, che è anzi bersaglio satirico di Licino,
maschera e porte-parole dell'autore (cf. Dubel, op. cit., p. 19), il viaggio desiderato da
Timolao nella Nave o i desideri ha diversi punti di contatto con il volo di Menippo.
Anch'egli parte dal rifiuto dei beni più comunemente ambiti (41); Hermes deve
incontrare Timolao e fornirgli i mezzi, un anello magico, tra le altre cose per il
volo (42); desidera volare ovunque e poter vedere ogni meraviglia da una parte
all'altra della terra, suoi obiettivi sono l'esplorazione del cielo e la soddisfazione
della conoscenza scientifica; non mancano altri motivi comuni come la critica del
tiranno e l'osservare le guerre da luogo sicuro; infine anche questo personaggio
diventerebbe pari a un dio (44). Timolao-non diversamente da Menippo anche se
il segno è opposto - appare come un folle per il suo desiderio di volare (45). Un
confronto può essere fatto anche col volo della nave di Luciano nelle Storie vere. Cf. Anderson, op. cit., p. 30 ss.

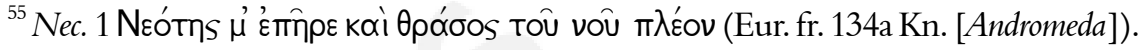
Per i paralleli tra Icaromenippo e Negromanzia cf. Camerotto, op. cit., 2009a, p. 11-13.

${ }^{56}$ Icar. 3, 23.

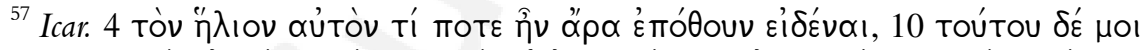

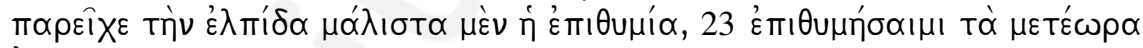
$\varepsilon \kappa \mu \alpha \theta \varepsilon \hat{\imath} \nu$. Per il desiderio della conoscenza che motiva il viaggio cf. Cont.

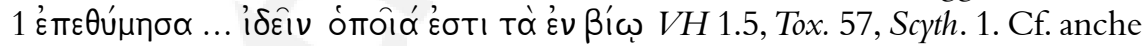
Georgiadou-Larmour, op. cit., p. 13-22.

${ }^{58}$ Si può confrontare in Demon. 3 l'impulso originario del percorso filosofico di Demonatte che attraverso il distacco dai beni conduce all'eleutheria, alla parrhesia e all'aletheia, virtù ciniche e virtù della satira. Vi si può individuare il principio cinico che rovescia l'opinione corrente e sovverte le convenzioni, riassunto nella definizione

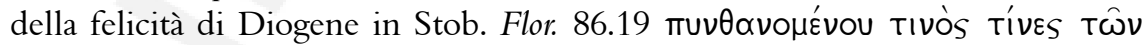

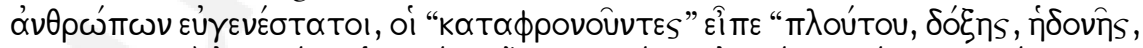

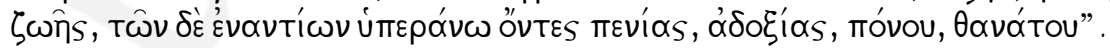

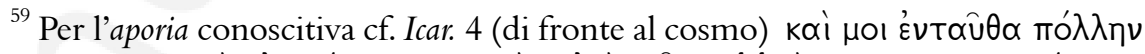

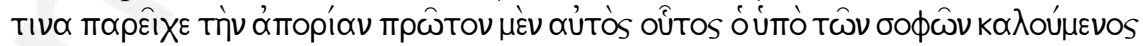

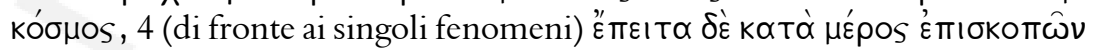


insormontabile sul piano conoscitivo, che insieme è anche difficoltà morale. È a questo punto che è necessario un progetto diverso come unica possibilità per sciogliere il problema: bisogna salire in cielo o altrimenti scendere sotterra. Limpresa fantastica si annunzia per l'appunto come l'unica soluzione possibile. ${ }^{60}$ È necessario discostarsi dai mezzi e dalle vie normali e l'impresa diviene un qualcosa di audace e inconsueto, un Tó $\lambda \mu \eta \mu \alpha,{ }^{61}$ che ha bisogno di un ardimento dell'ingegno e dell'azione. ${ }^{62}$ È nel concreto una $\pi \varepsilon \hat{\imath} \rho \alpha$, uno sperimentare e un mettersi alla prova, ${ }^{63}$ che procede per tentativi e gradi sempre più audaci, in cui si manifestano e trovano applicazione le qualità dell'eroe satirico. Se la polimorfia e l'ambiguità sono un tratto costitutivo del personaggio, così vale per le sue azioni, il cui significato non è mai univoco, e conseguentemente vale lo stesso anche per le specifiche virtù del fare.

Naturalmente un'impresa come quella del volo o della catabasi comporta anche molte difficoltà e gravi rischi. Rimanendo all'Icaromenippo v'è il pericolo di precipitare, ancora secondo i paradigmi del mito (e della commedia) ma Menippo non sembra avere paura (Icar. 3). I primi tentativi di volo sono problematici, ma un po' alla volta egli prende sicurezza. ${ }^{64}$ Levandosi in alto è preso dalle vertigini, ma anche questa difficoltà viene superata. ${ }^{65}$ V'è poi la stanchezza, che si fa sentire in prossimità della luna. ${ }^{66}$

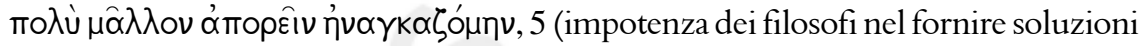

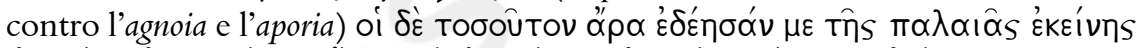

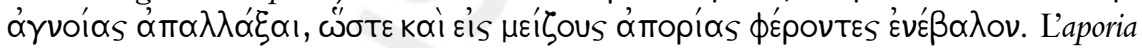
diviene visiva quando è il momento di osservare le azioni degli uomini dalla luna:

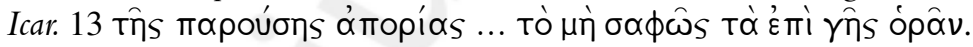

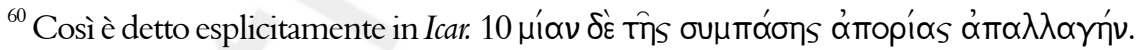

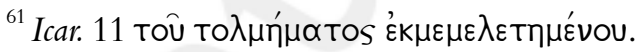

${ }^{62}$ Più precisamente v'è bisogno di un sophisma, ma entra in gioco anche l'idea della

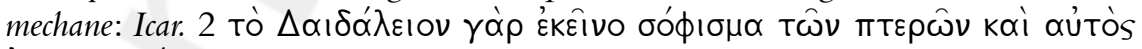

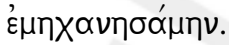

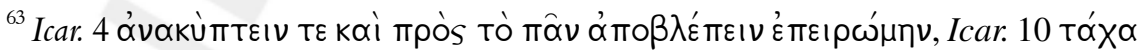

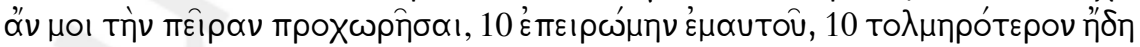

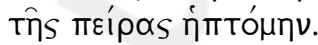

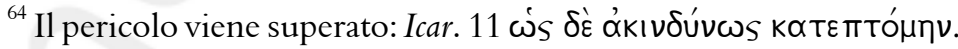

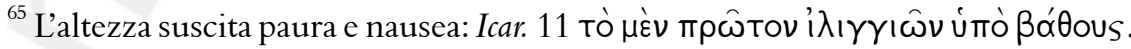

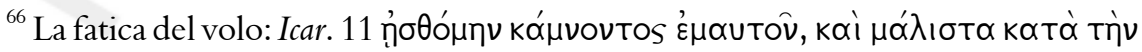

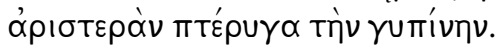


Una certa paura, dopo l'inatteso incontro con Empedocle e dopo le preoccupazioni per l'accesso al cielo, Menippo ce l'ha anche quando è arrivato alla sua ultima meta e viene fatto entrare nelle sedi degli dei, e un bello spavento ancora se lo prende quando si trova al cospetto di Zeus. ${ }^{67}$ E se poi guardiamo alla Negromanzia, non minori pericoli comporta il viaggio che conduce ai luoghi dai quali si sa che di norma non v'è ritorno.

La satira - teniamolo a mente - è l'obiettivo del nostro complicato eroe. Attraverso l'impresa inedita deve crearsi una specola che stia al di fuori della realtà per poter osservare tutto da una prospettiva straniante. Per fare ciò l'eroe satirico deve essere tolmeros, ossia audace e privo di inibizioni nel violare ogni limite e convenzione, come lo sarà poi per altri rispetti anche nell'osservazione e nelle parole dell'attacco satirico. Per il suo volo, Menippo

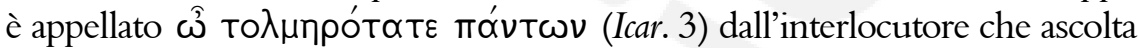
stupefatto il racconto. V'è il coraggio, ma è anche un terribile azzardo e forte è il senso dell'eccesso. La tolme non è comunque audacia inconsapevole, è fatta di riflessione, di autoironia, e di tentativi. Menippo in principio tenta anche le vie normali, si affida ai filosofi - la tolme ancora non agisce. ${ }^{69}$ Il nostro

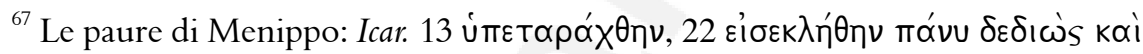

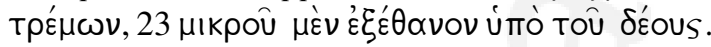

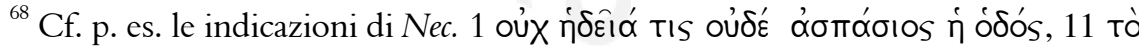

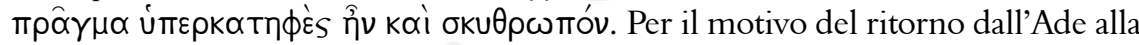

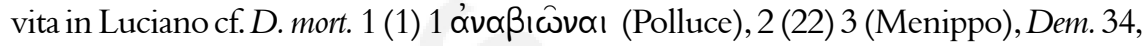
Pseudol. 5, Pisc. 4, 14, 52 (i filosofi), Luct. 2 (a pochissimi Plutone concede di ritornare), 5 (Alcesti, Protesilao, Teseo, Odisseo). In Cont. 1, con un'operazione paradossale, addirittura Caronte, il traghettatore dei morti, lascia l'Ade per salire sulla terra per un giorno - non diversamente da Protesilao - a osservare la vita degli uomini nel ruolo di personaggio satirico (cf. Jacobson, op. cit., p. 222 "Charon's 'tour' - at bottom the converse of Odysseus' in book 11”). Anche nel mito platonico di Er si tratta di un

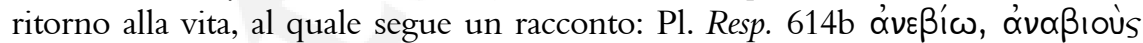

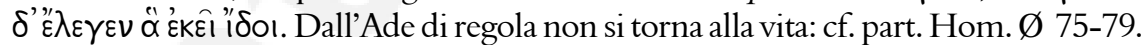

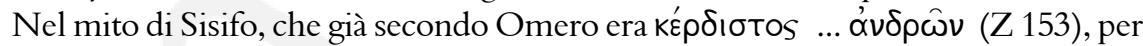
poter varcare due volte l'Acheronte bisogna essere по入úı $\delta$ Is (Alc. 38a.5-8 V., cf. Theogn. 702-712). In Ar. Ra. 80 ss. Dioniso si preoccupa fin dall'inizio del ritorno, e prevede che un Euripide per l'appunto mavoûpyos gli possa essere d'aiuto. Nei Demi di Eupoli vengono evocati dall'Ade Solone, Milziade, Aristide e Pericle a consigliare la città che è rovinata dai demagoghi. Sul ritorno impossibile dall'Ade com'è definito anche da Luciano in D. mort. 13 (13) 3, Luct. 2 - cf. p. es. Eur. Herc. 297

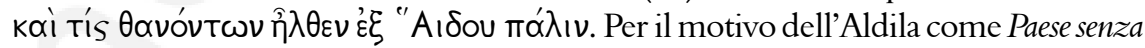
ritorno, di derivazione orientale, cf. Baslez, op. cit., p. 90 ss.

${ }^{69}$ Icar. 10 ๙่ 
eroe trova la lucidità e l'ardimento di cercare una propria via per la ricerca scientifica ed etica: passa alla dimensione ambigua e altra che per l'appunto è propria della tolme. Lapplicazione consiste nell'esperimento del volo, ${ }^{70}$ tentativo che è sfida impossibile per chiunque altro possieda le risorse univoche della normalità. Alla fine la sua audacia appare manifesta, perché essa va contro tutto e contro tutti, e anche gli dei sono giustamente preoccupati

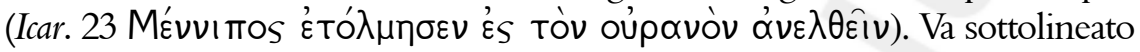
che la tolme è virtù non semplice, normalmente anzi appare di segno negativo, come indica la sua ripetuta applicazione nella critica dei filosofi - e come avveniva già nella Commedia. ${ }^{71}$ Essa giunge ad assumere i tratti della hybris già nella realizzazione dell'impresa, che difatti viene paragonata a uno dei modelli mitici di tracotanza, l'epico tentativo di dare l'assalto alle sedi degli dei da parte di Oto ed Efialte (Icar. 23). E sempre per questo motivo alla fine Menippo viene privato delle ali (Icar. 34), in modo tale che egli non possa più tornare in cielo e che nessun altro ne possa seguire le tracce, per la pericolosità dell'ascesa e dell'esempio: infatti il volo di Menippo rischia di incrinare le categorie fondamentali che stabiliscono l'assetto e i rapporti tra gli uomini e gli dei. Ma la satira non teme nulla, Menippo non si fa scrupoli di osservare e criticare anche ciò che avviene lassù in cielo dov'è riuscito ad arrivare, e gli dei, vecchi e nuovi, sono spesso e volentieri oggetto della satira lucianea.

\section{Le virtù del vedere}

All'eroe satirico appartiene la passione da philokalos ${ }^{72}$ dell'osservare (e ascoltare) ogni cosa. Nell'Icaromenippo, una volta raggiunta la specola della

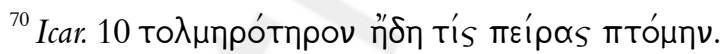

${ }^{71}$ Cf. per le azioni dei filosofi, regolarmente di segno negativo, Icar. 6 દ́ тó $\lambda \mu \omega \nu, 8$

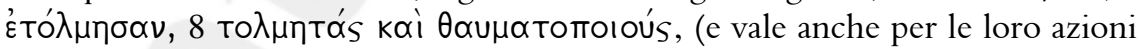
ignominiose che nascondono nel buio della notte, 21 тा то $\lambda \mu \omega \hat{\nu} \tau \alpha$

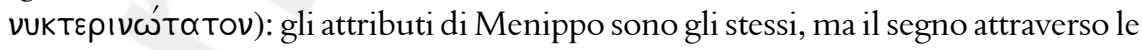
dinamiche fantastiche della creazione satirica diviene positivo, senza comunque perdere l'ambiguità e non senza l'autoironia. Per l'uso del termine per la definizione della mixis compositiva cf. Camerotto, op. cit., 2009a, p. 5 n. 16. Per le valenze ambigue dei termini nella commedia cf. Camerotto, op. cit., 2007, p. 273 ss.

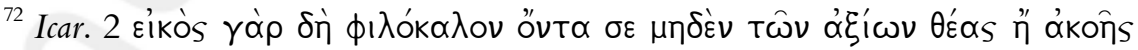
$\pi \propto \rho \alpha \lambda ı \pi \varepsilon \hat{~}$. In Pisc. 20 Parresiade, ipostasi dell'autore satirico, non manca di essere

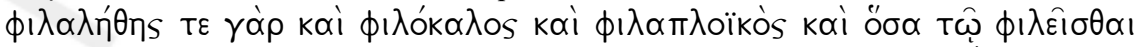

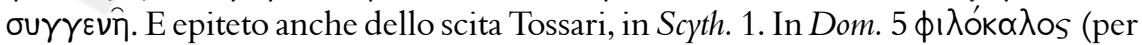
l'osservazione estetica) sta significativamente in opposizione a фı 
luna, prima grande tappa del viaggio satirico, Menippo ha bisogno della virtù specifica della visione satirica, l'oxyderkia, una potenza visiva straordinaria, che lo contrappone alle false pretese dei filosofi, ${ }^{73}$ suoi antagonisti e primo bersaglio satirico nel racconto. Per il suo ruolo egli non può sicuramente accontentarsi del magnifico spettacolo del globo terracqueo, anzi ne è quasi deluso e amareggiato perché non vede quello che gli interessa. L'obiettivo più concreto è osservare fin nei minimi particolari ciò che fanno gli uomini sulla terra. Perciò Menippo deve assumere gli attributi mitici di Linceo e quelli epici dell'aquila (Icar. $14 \alpha_{\alpha} \varepsilon \tau \hat{\omega} \delta \varepsilon S \beta \lambda \lambda^{\prime} \pi O ।$ ) fino a divenire

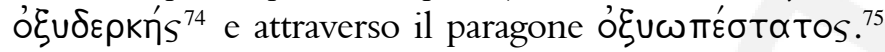

$\mathrm{E}$ in aggiunta, per mezzo dei versi epici della panopsia, la sua vista non è da meno di quella di Zeus (Icar. 11). ${ }^{76}$ Una vista totale, che unisce alla grande visione telescopica quella microscopica. Lo sguardo spazia da una regione all'altra della terra e Menippo può vedere simultaneamente ciò che avviene in Libia a sud e all'estremo nord fra gli Sciti (Icar. 15), e ancora può osservare in una teoria spettacolare le attività di Geti, Sciti, Egizi, Fenici, Cilici, Spartani e Ateniesi. Una vera impresa sia per l'azione sia per il racconto, ${ }^{77}$ pure esso costretto a ricorrere all'aiuto degli opportuni paradigmi epici. Per il racconto Menippo diventa un Omero: per descrivere tutto quello che ha visto utilizza come modello la rappresentazione artistica e panoptica dello scudo di Achille che nell'Iliade

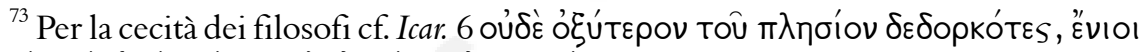

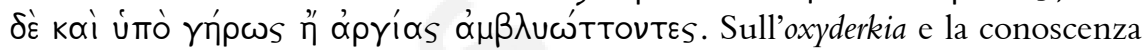
autoptica dei fatti è costruita in Philops. 15 la contrapposizione tra Tichiade (la voce satirica) e i suoi avversari creduloni.

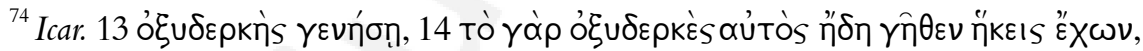

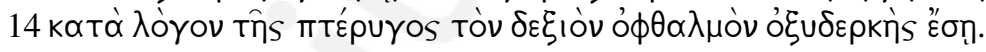

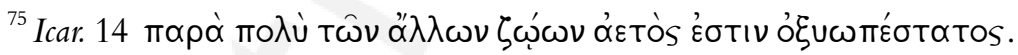

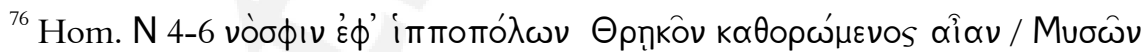

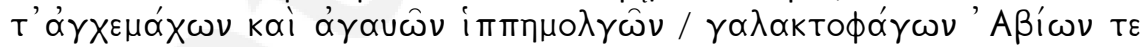

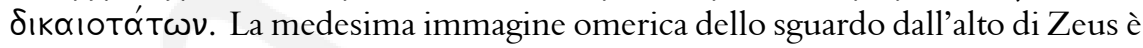
reimpiegata ancora di seguito nella narrazione in Icar. 16, 27 (Hist. conscr. 49, Lex. 15). La panopsia epica dell'eroe satirico lucianeo che muove il suo sguardo da una regione all'altra della terra ritorna in maniera spettacolare in Cont. 5 (Somn. 15).

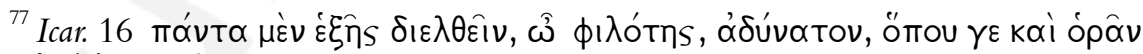

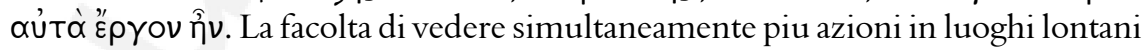
tra loro è un adynaton dello storico, ma Menippo che riprende anche i paradigmi della storiografia se lo può permettere in funzione della satira (Polyb. 12.4c.4, cf. Saïd, op. cit., p. 156). Per la difficoltà di raccontare tutto, con la preterizione di ascendenza epica, cf. D. mort. 6 (20) 1, Cont. 2, etc. 
univa il cosmo e la vita degli uomini in un'unica visione conclusa dal circolare fiume Oceano. Ma la speciale vista dell'eroe satirico ha anche il potere di raggiungere ogni minima cosa e perfino le larve di zanzara. Soprattutto deve poter cogliere le azioni nascoste e i vizi degli uomini. È una vista che come quella di Linceo non incontra ostacoli e penetra senza difficoltà nelle regge come nei lupanari. ${ }^{78}$ A questo potere straordinario che gli permette di osservare tutto e tutti in qualsiasi luogo si aggiunge la facoltà di vedere non visto, che sottolinea il distacco dell'eroe satirico dall'oggetto dell'osservazione. ${ }^{79}$ Anche sul piano temporale è una vista totale, la quale supera i vincoli che sono imposti a qualsiasi mortale poiché essa lascia osservare contemporaneamente azioni che si compiono in molti luoghi lontani tra loro. ${ }^{80}$ Ma permette anche di stare a guardare nel loro svolgersi vicende che appartengono a momenti diversi riunite tutte in un'unica multipla visione sincronica. ${ }^{81}$ È la potenza della satira, che regolarmente si manifesta nella galleria di figure dell'Aldilà, scene in cui l'eroe satirico incontra insieme personaggi del mito e figure storiche delle più diverse epoche fino all'attualità.

Per fare satira non basta però neppure questa vista eccezionale. Essa diventa efficace solo se è la vista di un personaggio che sa adottare un modo di pensare e di interpretare ciò che vede tutto particolare. ${ }^{83}$

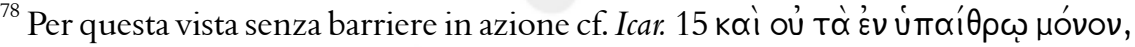

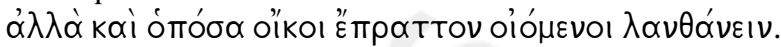

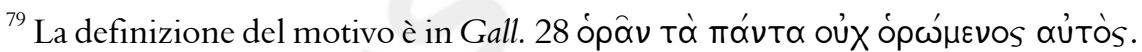
In $V H 1.26$ attraverso lo speciale specchio lunare Luciano dice di aver visto i suoi familiari e si pone il problema se essi abbiano visto lui.

${ }^{80}$ Per l'importanza del motivo, che avrà grande sviluppo nella tradizione satirica europea, cf. Relihan, op. cit., 1996, p. 269, che lo definisce come "the miraculous universal vision

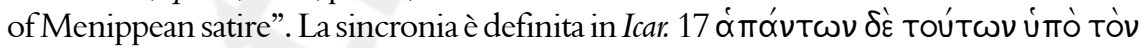

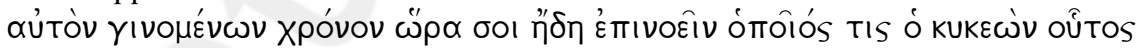
हффа'

${ }^{81}$ In Bis acc. 2 la vista di Zeus, della quale Menippo eredita la potenza, è paragonata a quella del pastore Argo, dotato di cento occhi.

${ }^{82}$ Cf. p. es. D. mort. 20 (6), VH 2.15-19, part. 17 (nell'Isola dei Beati), 31 (nell'Isola degli Empi). Il valore di una definizione per la panopsia nel tempo e nello spazio è la visione dei morti nella piana Acherusia in Nec. 15, i morti appartengono a popoli

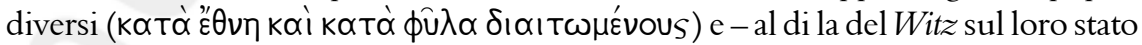

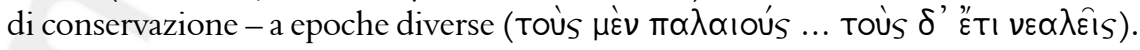

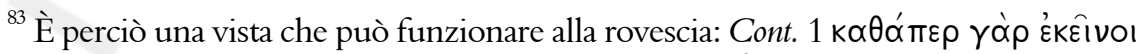

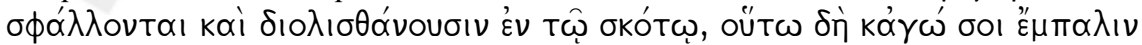

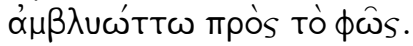


Abbiamo un eroe della satira che è strano per le sue qualità, ma che soprattutto sperimenta logiche altre. È partito dal rifiuto delle convenzioni, ha abbandonato le opinioni consolidate e tradizionali, e nemmeno ha dato fiducia ai filosofi e a tutte le loro infinite e contraddittorie teorie, per cercare una propria via. Per la satira è necessaria infatti una prospettiva diversa, perché solo attraverso lo straniamento è possibile osservare e vedere veramente ciò che accade. Se può apparire come straniero da tutti i punti di vista a partire da quello della polis e se di regola sta ai margini della società o addirittura diviene estraneo alla comunità umana, ${ }^{84}$ egli esce anche dalla logica comune per adottare una logica diversa com'è per esempio quella del sogno. ${ }^{85}$ Così se a sostenere il volo di Menippo sono i suoi pensieri aerei, ${ }^{86}$ la logica dell'uomo che sta sopra le nuvole o che scende tra i morti apparirà come follia. ${ }^{87}$ I paradigmi lucianei divengono ancor più evidenti: anche in questo si incrociano di nuovo nella figura dell'eroe satirico la filosofia e le rappresentazioni di Socrate, le aspirazioni insieme fantastiche e critiche della Commedia, e soprattutto le parole e i comportamenti controcorrente dei Cinici. ${ }^{88}$

${ }^{84}$ Cf. la definizione dei comportamenti del filosofo cinico in Vit. Auct. $11 \mu ı \alpha \rho \grave{~}$

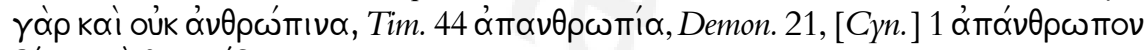
ßíov kai

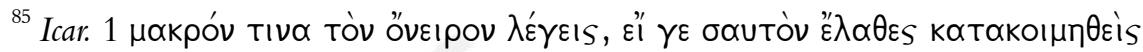

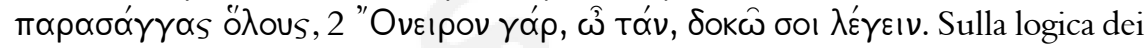
sogni, che tutto rende possibile, cf. Gall. 5-8. La logica altra dei sogni serve non a caso da paragone per il percorso filosofico satirico dello stesso "Luciano" in Nigr. 5.

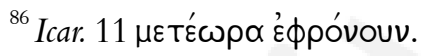

${ }^{87}$ È ciò che ritiene l'interlocutore di Menippo di fronte alle parole in versi del filosofo di ritorno dall'Ade in Nec. $1 \alpha^{\prime} \lambda \lambda^{\prime} \hat{\eta} \hat{~ \pi \alpha \rho \alpha \pi \alpha i ́ \varepsilon ı s . ~ P e r ~ i l ~ v o l o ~ d e l l ' I c a r o m e n i p p o ~}$ si può confrontare in particolare Nav. 45, dove il desiderio di volare è bollato come follia che ha bisogno dell'elleboro. In Nigr. 6 Luciano o il suo alias, dopo il viaggio

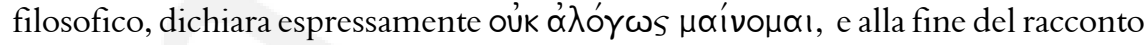
anche l'ascoltatore diviene partecipe della medesima follia (Nigr. 38).

${ }^{88} \mathrm{Cf}$. la definizione attraverso le categorie della follia per la disposizione satirica e

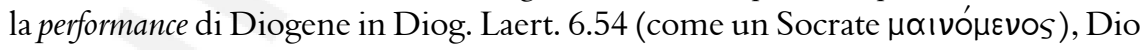
Chrys. Or. 3.36, 9.8. Cf. anche la follia del cinico Monimo che getta via le monete in Diog. Laert. 6.82. Cf. Bosman, op. cit., p. 100: " The role of the fool is more appropriate, in the sense of not conforming to group standards, of having special power because of a privileged position, and of being admired. However, his 'foolish' appearance has nothing to do with stupidity or incompetence; from the Cynic perspective, this ought to be the norm, society itself being the foolish party". 


\section{Le virtù del dire: la parrhesia in azione}

Il nostro eroe, quando dall'osservazione passa all'attacco satirico, ha bisogno di ancora nuove qualità che sono in sostanza quelle del dire. Queste virtù divengono evidenti nella rappresentazione che ne dà chi è bersaglio della satira. Perciò può essere conveniente prendere in considerazione una di quelle opere lucianee come il Pescatore o $i$ redivivi, dove il porte-parole e alias dell'autore ${ }^{89}$ è Parrhesiades: questo eroe della parola critica e libera ${ }^{90}$ lo vediamo costretto a difendersi di fronte alla reazione indignata e violenta dei filosofi che sono stati messi alla berlina in un'opera precedente, nella Vendita all'asta delle vite.

Un fatto prima di tutto appare significativo per la nostra prospettiva di analisi. Oltre all'ira feroce che lo vorrebbe morto, Parresiade deve subire due specifiche minacce che sottolineano di cosa è fatta la satira: ${ }^{91}$ coloro che sono stati bersaglio dei suoi attacchi vogliono che all'autore siano strappati

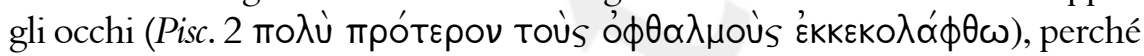
come abbiamo visto sono il potente e indispensabile strumento dell'osservazione satirica, e insieme pretendono che gli sia tagliata la lingua

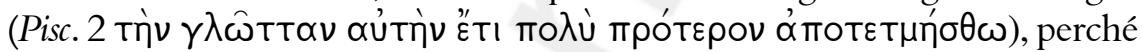
è una lingua speciale, ossia maledica, dalla quale vengono le parole della satira che sono pronunciate nelle performances pubbliche e spettacolari, con gli effetti che ne conseguono. L'attenzione è proprio sulle parole, è per esse che si scatena la rabbia e la furia vendicativa di chi ne è colpito. La reazione prodotta è così forte che lo stesso autore ne sembra stupito: è per le parole che i suoi avversari lo vogliono addirittura morto (Pisc. 3 vûv oûv

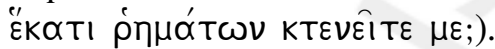

Lespressione verbale che qui ci interessa è naturalmente un maledire, ed è così definita insistentemente e in vari modi proprio dalle vittime

${ }^{89}$ Cf. Branham, op. cit., 1989, p. 28-38. Per la relazione sul piano compositivo tra

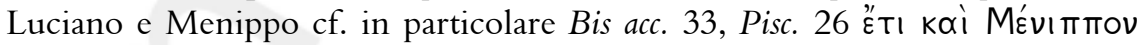

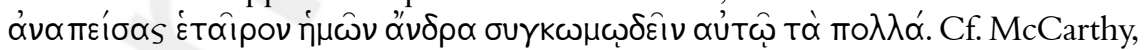
op. cit.; Hall, op. cit., p. 64-150.

${ }^{90}$ Sulla parrhesia nel mondo antico, tra i molti contributi, cf. Radin, op. cit.; Scarpat, op. cit.; Momigliano, op. cit.; Foucault, op. cit.; Spina, op. cit., 1986; Ammendola, op. cit., e i diversi interventi del volume di Sluiter - Rosen, op. cit. Sulla parrhesia in Luciano, che ha tratti prevalentemente cinici (cf. Diog. Laert. 6.69), cf. Visa-Ondarçuhu, op. cit. Cf. anche supra $\$ II.1.

${ }^{91}$ Fare satira comporta molti rischi proprio per le reazioni che essa suscita: Pisc. 17

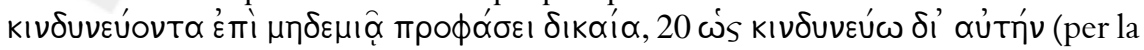
polymises techne, ossia per la satira). 
dell'attacco. V'è tutta una serie di insulti relativi alla parola e indirizzati contro Parresiade, i quali mettono in evidenza ciò che accade con la satira.

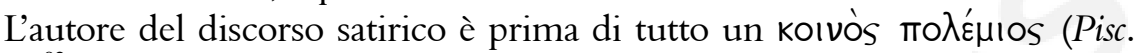
1), ${ }^{92}$ cosa che sottolinea fin dall'inizio due fattori: la satira, poiché produce

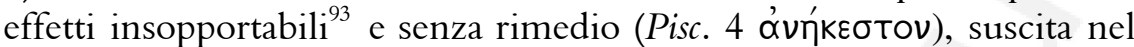
bersaglio una reazione ostile, immediata e profonda; ${ }^{94}$ l'eroe satirico - e non diversamente insieme a lui l'autore - si trova in una situazione che assomiglia a quella degli eroi del mito come poi a quella dell'eroe comico, ossia si trova solo contro tutti. ${ }^{95} \mathrm{E}$ il male che ha fatto merita definizioni

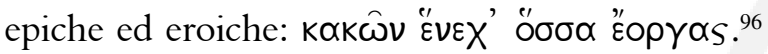

Per quello che dice, chi si fa carico della parola satirica è $\beta \lambda \alpha ́ \sigma \phi \eta \mu o s$, cioe "diffamatore" con tratti propri della dissacrazione (Pisc. 1), ${ }^{97} \mathrm{e}$ corrispondentemente le opere satiriche sono definite come $\beta \lambda \alpha \sigma \phi \eta \mu i \alpha_{S}$

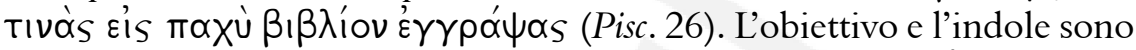
definiti perfettamente da quelli che sono stati colpiti: Pisc. 7 Ev $\alpha$ toûtov

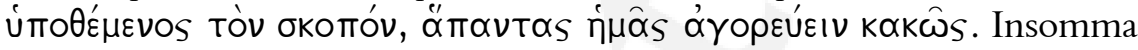
Parresiade vive con un unico scopo, quello di parlar male. Perciò è

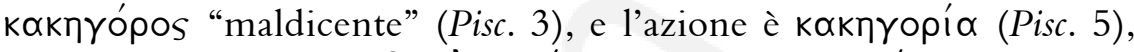

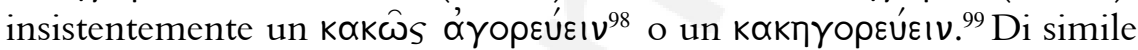

${ }^{92}$ Ma per primo a dichiarare la guerra è ovviamente chi fa satira: Pisc. 17 oú yờ tôls

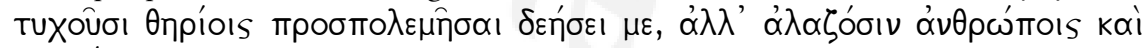

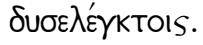

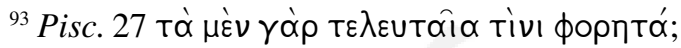

${ }^{94}$ A definizione dell'inimicizia è usata una paradigmatica frase omerica: oủk हैoTI

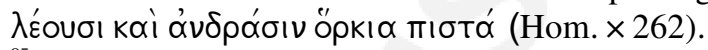

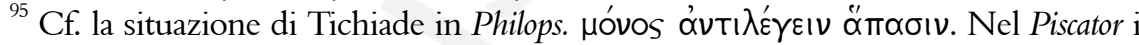

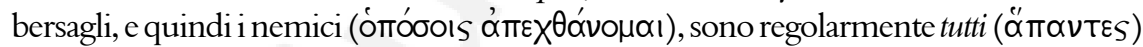

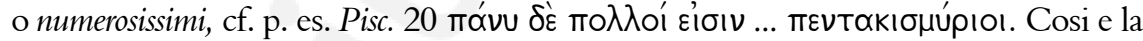
caratteristica della parrhesia cinica che attacca tutti (in questo caso con la critica di

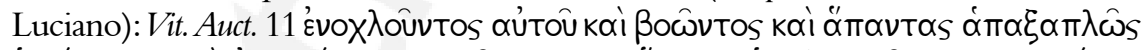

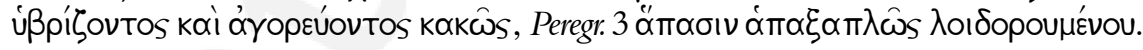
${ }^{96}$ Hom. Â 57. Il peso dell'espressione va anche al di la della specifica citazione (Paride meriterebbe di essere lapidato dagli stessi Troiani per tutti i mali di cui è stato causa per la sua città) e può richiamare anche le azioni terribili dell'aristeuon, con tratti ferini e mostruosi (cf. in proposito Camerotto, op. cit., 2009b, p. 68, p. 167 ss., con l'indicazione delle formule specifiche).

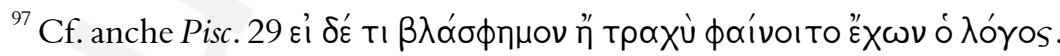

${ }^{98}$ La medesima definizione della maldicenza ritorna in Pisc. 4, 14, 15, 25, 29, 37, cf.

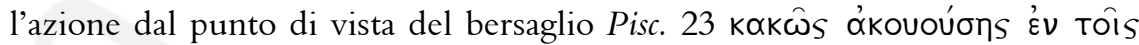

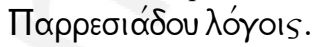

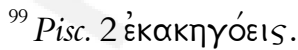


tenore è la definizione della satira attraverso i verbi specifici dell'ingiuria, con l'azione applicata alle cose che sembrerebbero essere le più importanti nell'opinione comune, come nella denunzia $\lambda \circ ı$ $\delta \rho \varepsilon \hat{\imath} \theta \propto$ । Tốs kpeítтoбıv (Pisc. 2) ${ }^{100}$ Si produce un vero e proprio ribaltamento,

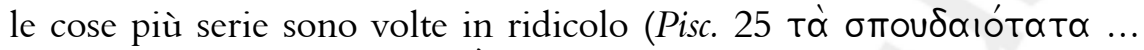

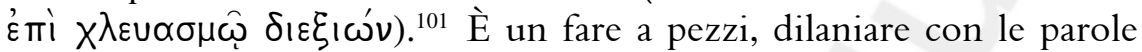

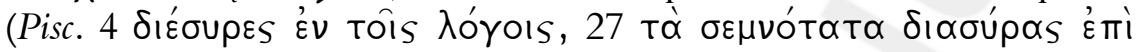

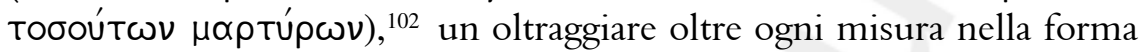

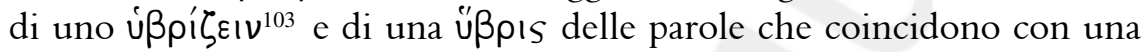

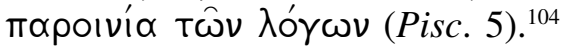

Le parole sono guidate dalla sfrontatezza (Pisc. 5 óvoıı e da una audacia, ancora una tolme, che appare alquanto pericolosa

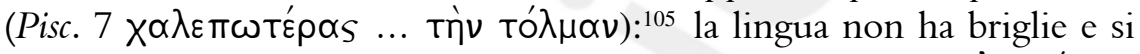
accompagna a una dissennatezza fuori da ogni legge (Pisc. $3 \propto \alpha x \propto \lambda i ́ v \omega \nu$

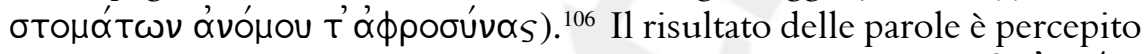
come un torto e una iniquità che deve essere punita (Pisc. 7 Tṇ $\alpha$ dı ıíạ,

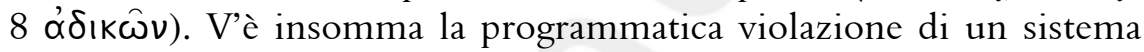
costituito e in base alle convenzioni sociali riconosciuto da tutti come prestigioso. Quello che fa la satira è una specie di empietà. Perciò Parresiade diviene un $\theta$ píov (Pisc. 2), ${ }^{107}$ bestia e mostro insieme, è

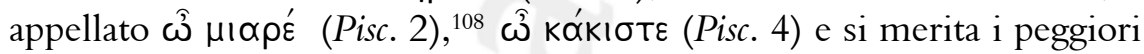

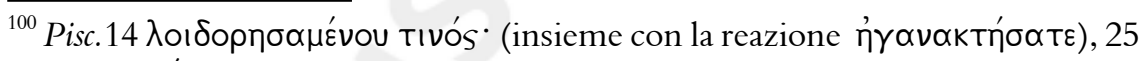

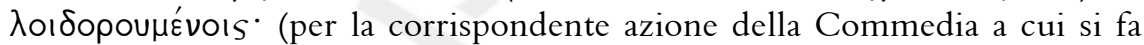

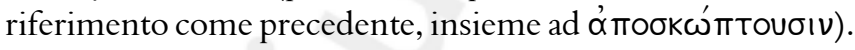

${ }^{101} \mathrm{Su}$ questo rovesciamento assiologico cf. le definizioni di Bis acc. 33 e cf. Camerotto, op. cit., 2009a, p. 1-8.

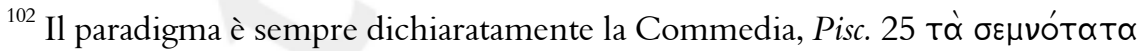

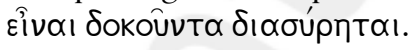

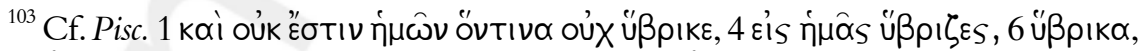

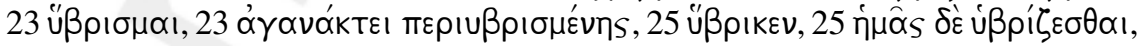

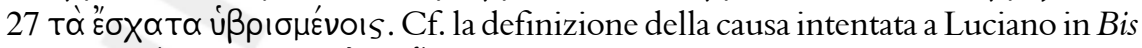

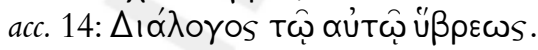

${ }^{104}$ Per l'associazione tra hybris e paroinia cf. I. trag. 21, Salt. 48, Deor. Conc. 5, Prom. es 5.

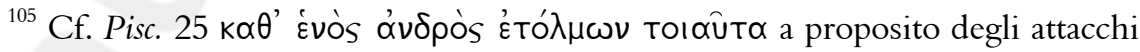
satirici della Commedia.

${ }^{106}$ Con il reimpiego qui di una definizione euripidea, cf. Eur. Bacch. 386 ss.

${ }^{107}$ È poi usato anche per i bersagli della satira (Pisc. 17), ma nel suo uso per la voce critica richiama ovviamente i modi cinici dell'attacco satirico. 
epiteti corrispondenti come katápatos "maledetto" (Pisc. 1, 15), ${ }^{109}$

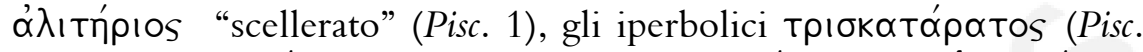

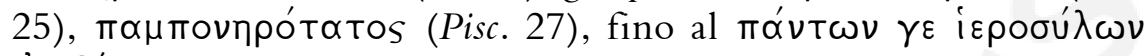

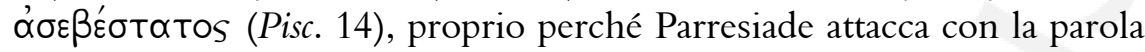
anche ciò che è per tutti - almeno nelle apparenze - cosa sacrosanta e

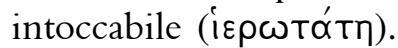

Ma queste ingiurie si trasformano in virtù se guardiamo come Parresiade se le è conquistate. Le qualità di cui è dotato sono straordinarie abilità del dire. Se è definito con un segno negativo mavoûpyov Év tốs

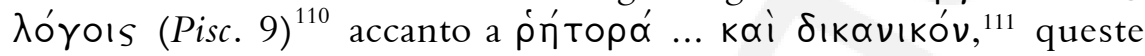
caratteristiche indicano la pericolosità di Parresiade proprio sul piano

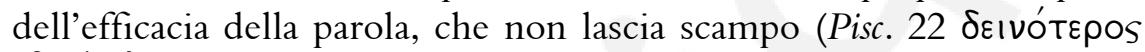
oútós દoTIV). Questa abilità retorica si è costruita attraverso un percorso

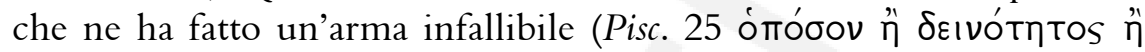

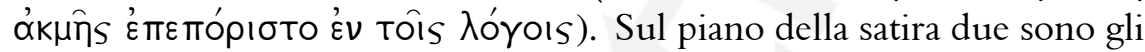
effetti di questa deinotes. Il primo è la straordinaria capacità di rappresentazione dei vizi, attraverso una enargeia che trasforma l'oggetto narrato o descritto in qualcosa di vivo e presente davanti agli occhi più ancora che agli orecchi di chi ascolta. E in più v'è una incredibile potenza icastica della parola che permette di rappresentare non solo i corpi ma addirittura anche le anime: ${ }^{112}$

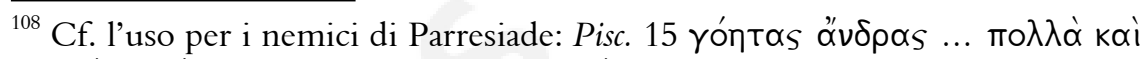

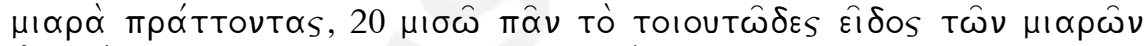

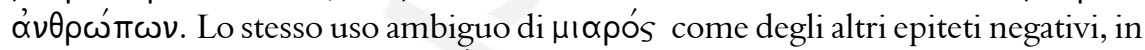
particolare navoûpyos e tovmpós, e nella Commedia, dove vale per l'eroe comico come per i suoi nemici, cf. Camerotto, op. cit., 2007, p. 267, p. 273 ss.

${ }^{109} \mathrm{Nel}$ rovesciamento finale delle parti l'epiteto è applicato ai falsi filosofi: Pisc. 46

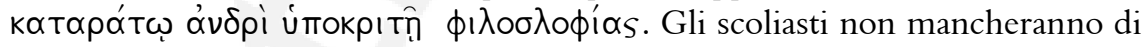
usare il medesimo epiteto contro lo stesso Luciano, a commento dei suoi testi.

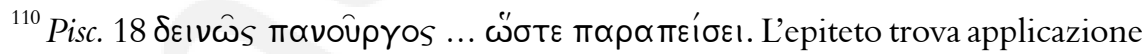
per Prometeo sempre in relazione all'efficacia della parola (Prom. 4

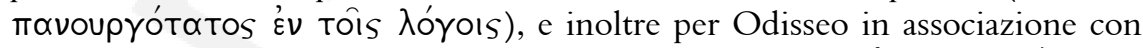
l'inganno del nome nell'episodio del Ciclope (D. mar. 2 [2] 2 ó паvoupyótatos

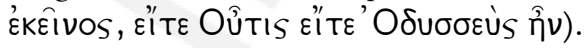

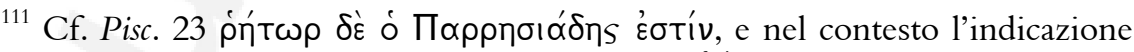

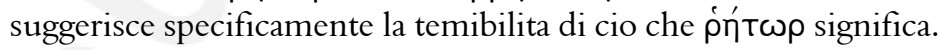

${ }^{112}$ Per questa speciale enargeia che trova qui applicazione in funzione della satira, cf.

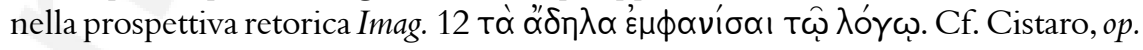
cit., p. 116-118. 


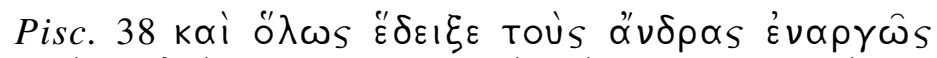

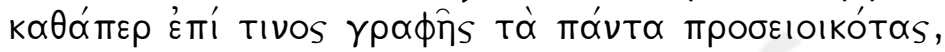

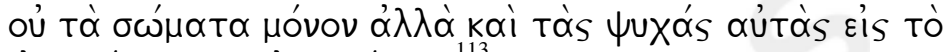

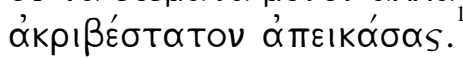

Ciò si verifica regolarmente davanti all'ampio pubblico che affolla le performances sofistiche, ${ }^{114}$ che per Luciano è fatto in primo luogo dei pepaideumenoi: ${ }^{115}$ le parole e ciò che esse dicono diventano $\phi \hat{\eta} \mu \alpha ı$ con un impatto più vasto e più duraturo dell'occasione. ${ }^{116}$ Grazie alla destrezza retorica entra in azione la forza di persuasione, ${ }^{117}$ che diviene successo della performance e che per la satira si manifesta in maniera particolare, ossia attraverso il riso critico e distruttivo, nel quale è coinvolto il pubblico e del quale vedremo poi il funzionamento e la potenza logica e comunicativa:

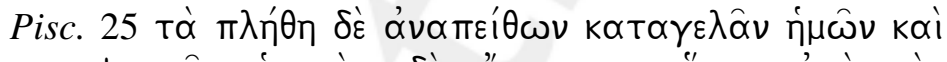

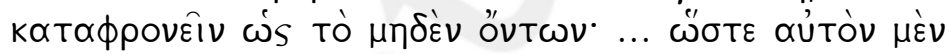

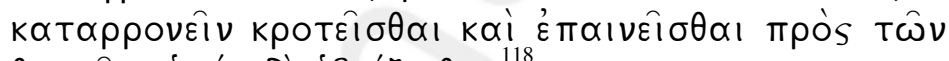

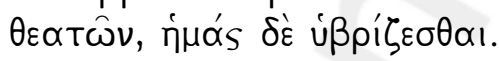

Ma non è questione solamente di abilità retorica. Le virtù fondamentali (prima di tutto già socratiche e ciniche) sono dichiarate dallo stesso nome del protagonista, che appare quale un vero e proprio

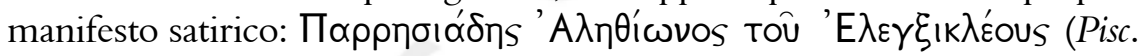
19). Esse diventano personificazioni che agiscono sulla scena teatralizzata del dialogo. ${ }^{119}$ Aletheia, la Verità, è la più importante: è descritta nella sua sfuggevolezza e problematicità, ed essa è nella personificazione allegorica

113 "Insomma ce li ha rappresentati al vivo, come in un dipinto, somiglianti in tutto, raffigurando con estrema precisione non soltanto il corpo, ma anche l'anima”.

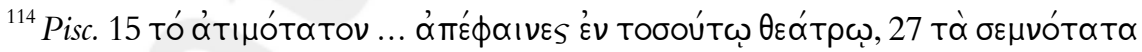

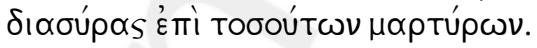

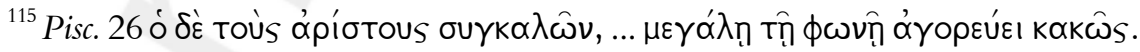
Sul pubblico di Luciano cf. Camerotto, op. cit., 1998, p. 264-277.

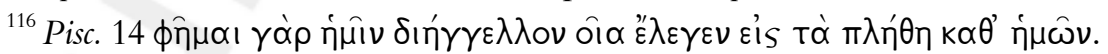

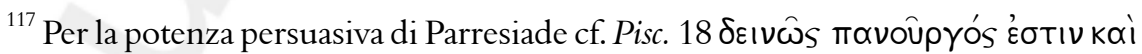

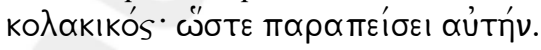

118 "Convince le folle a deriderci e a tenerci in conto di nulla, ... in maniera tale che egli è applaudito ed elogiato dagli spettatori, mentre noi veniamo oltraggiati”. In

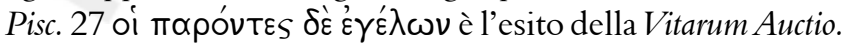

${ }^{119}$ Sulle personificazioni lucianee cf. Dolcetti, op. cit. 
il principale sostegno e difesa di Parresiade (Pisc. 16 ouvńyopov), il discrimen che nel giudizio finale rovescia le posizioni e i segni negativi in positivi.

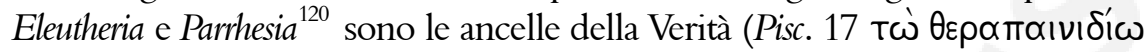

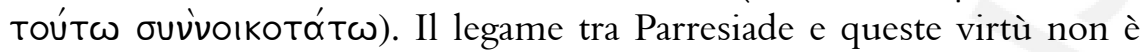
solo nominale: per la sua arte egli si dichiara $\phi ı \lambda \alpha \lambda \eta \dot{\theta} \theta \eta$ s (Pisc. 20) e

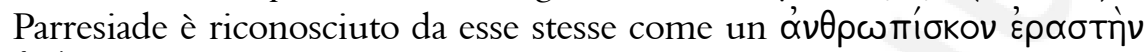

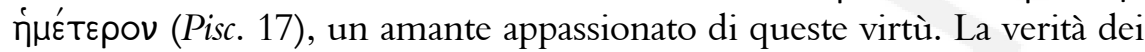

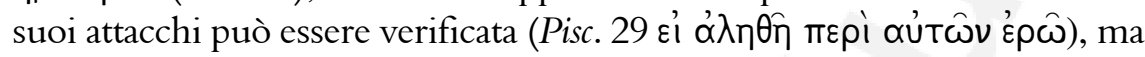
soprattutto è qui Aletheia in persona ad apporvi il suo sigillo (Pisc. 38

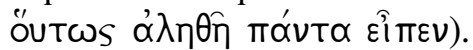

Nella scena allegorica - come anche nel nome - si aggiunge per la satira un'altra virtù fondamentale, Elenchos, che nella parte finale insieme a Parresiade mette alla prova e smaschera i falsi filosofi. È il principio attivo e polemico della satira, necessario per l'attacco e soprattutto per lo

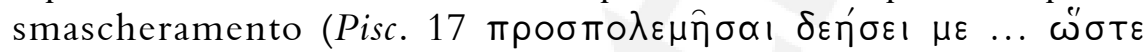

${ }^{120}$ Il legame "necessario" tra eleutheria e parrhesia è già in Democr. 68 B 226 D.-K.

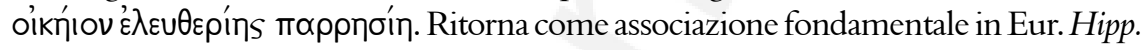
421 ss., e attraverso l'opposizione all'essere schiavi in Eur. Phoen. 392, mentre con un giudizio negativo si trova poi in Pl. Resp. 557e. Per la relazione inscindibile tra parrhesia

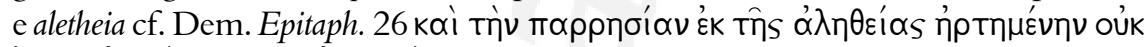

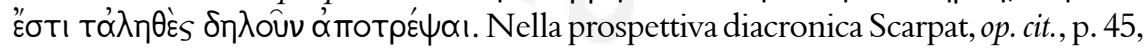
p. 58, part. 64 osserva che "della parrhesia politica il presupposto e la condizione era la libertà politica, della parrhesia cinica lo è la libertà morale: libertà assoluta dalle passioni, dal desiderio di possedere e di dominare, dal timore del tiranno e della morte, dalla paura della fame e delle privazioni: solo chi è completamente libero gode di completa parrhesia. Questo tipo di libertà diventa il maggior bene del filosofo cinico". L'ideale lucianeo è rappresentato da Demonatte che fin dall'inizio si distingue $\varepsilon$ đrí $\tau \varepsilon$

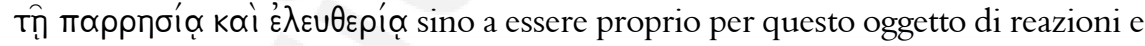
attacchi (Demon. 3, 11). Per l'associazione di eleutheria e parrhesia in Luciano cf. inoltre Peregr. 18, Calumn. 23, Pseudol. 1 (per definire Archiloco come paradigma della satira)

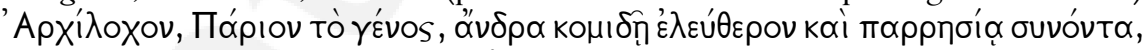

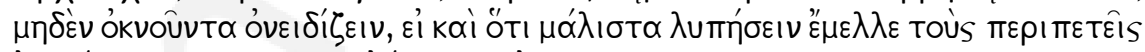

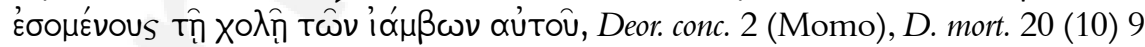

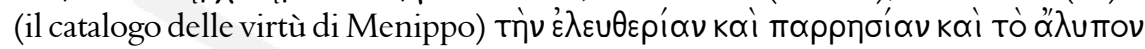

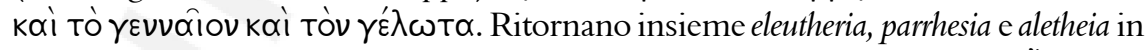
Demon. 3 ss., Nigr. 15, Lex. 17, Hist. conscr. 41, 61 (le virtù dello storico) äфoßos,

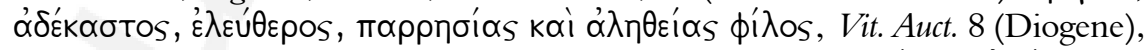

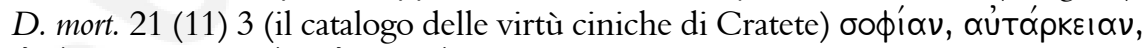
$\dot{\alpha}^{\prime} \lambda \dot{\eta} \theta \varepsilon ı \alpha \nu, \pi \alpha \rho \rho \eta \sigma i \alpha \nu, \dot{\varepsilon}^{\prime} \lambda \varepsilon \cup \theta \varepsilon \rho i ́ \alpha \nu$. La parrhesia si associa ancora all'aletheia in I. conf. 5, Tim. 36, Cont. 13, Alex. 47, Pseudol. 4 (con in più la personificazione di Elenchos), Abdic. 7, Hist. conscr. 44 (come fondamenti della storiografia), D. mort. 21 (11) 4. 


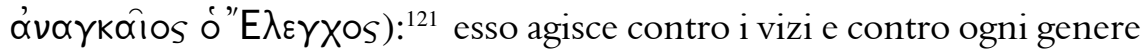
di poneroi in connessione con il $\mu \mathrm{\sigma} \sigma \mathrm{os}$ dichiarato che è parte della satira

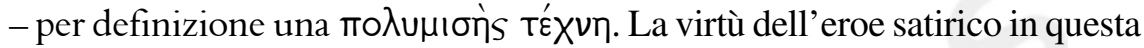

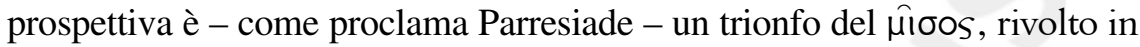

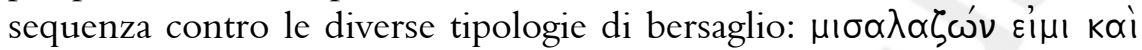

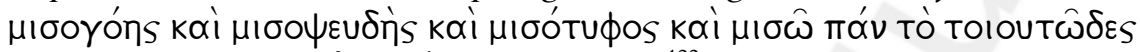

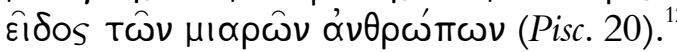

Il funzionamento della satira è ben descritto nei suoi diversi momenti e ha il suo compimento regolare nell'azione dell' $\varepsilon \lambda \varepsilon^{\prime} \gamma X \varepsilon ı$. La sequenza parte sempre dall' osservazione, e da questa nasce l'indignazione che conduce insieme allo smascheramento e all'attacco critico, ${ }^{123}$ verbale ma anche fisico. ${ }^{124}$

${ }^{121}$ Il primo ascendente di questà virtù sta naturalmente in Socrate, che anche da

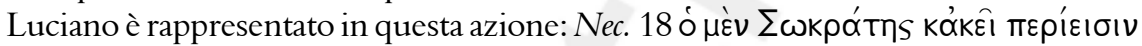

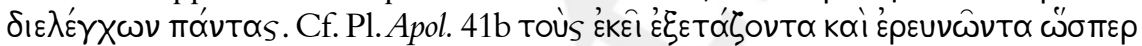

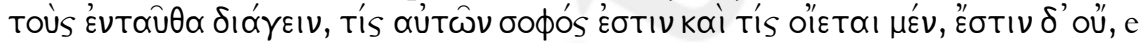

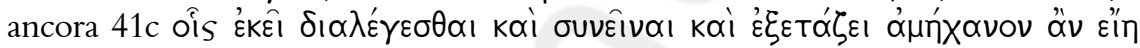

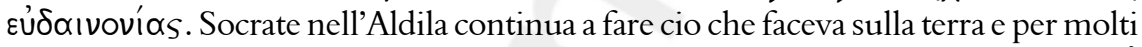
tratti, oltre che per l'elenchos, fa da precursore all'eroe satirico: $V H 2.17$ o

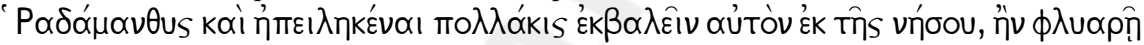

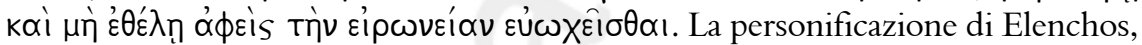
amico di Aletheia e Parrhesia, compare in Pseudol. 4 (cf. Dolcetti, op. cit., p 259 ss.). L'elenchos da virtù socratica diviene attraverso Diogene virtù cinica: Iulian.

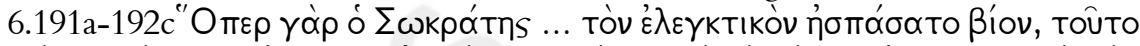

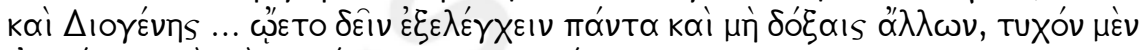

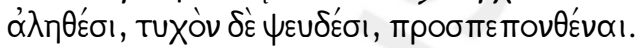

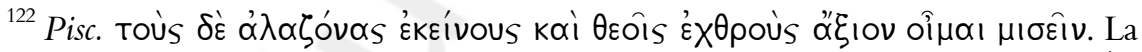

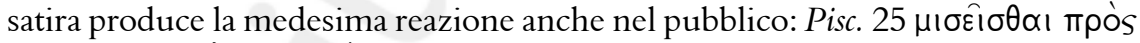

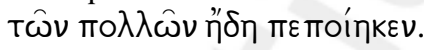

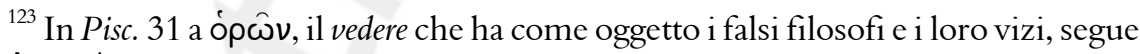

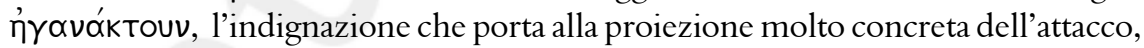

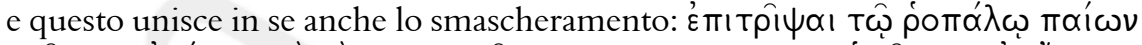

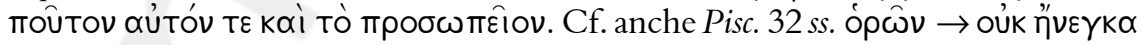

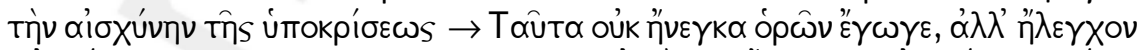

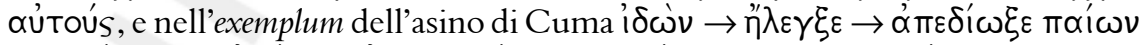

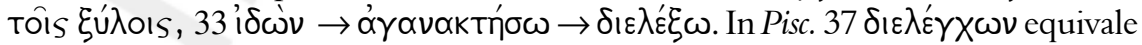

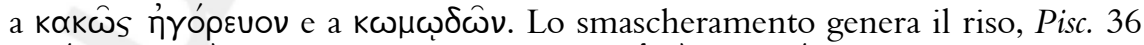

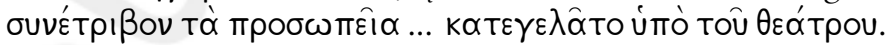

${ }^{124}$ L'attacco fisico - col bastone che serve anche a identificarlo (Diog. Laert. 6.23) - è in particolare una caratteristica di Diogene: Vit. Auct. 7 il bastone di Diogene, Pisc. 1, 24, 31 (Eracle e la clava), Fug. 14, Bis acc. 24. In Cat. 13 il bastone di Cinisco serve per il tiranno sul traghetto diretto all'Ade. Ma il bastone serve contro gli alazones già nella Commedia, cf. p. es. Ar. Pax 1121. 
V'è ancora un'altra immagine nel Pescatore o $i$ Redivivi che illustra l'effetto e il risultato ultimo della satira. Nel finale troviamo la scena di Aletheia che incarica proprio Parresiade insieme a Elenchos di togliere letteralmente la maschera - ossia gli attributi esteriori - ai falsi filosofi

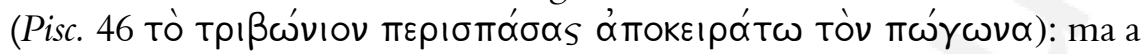
ciò v'è bisogno di aggiungere qualcos'altro, ossia un segno per rendere questi poneroi riconoscibili a tutti nella loro falsità e infamia. ${ }^{125}$ E sarà un marchio a fuoco ben in evidenza sulla fronte con il segno della scimmia

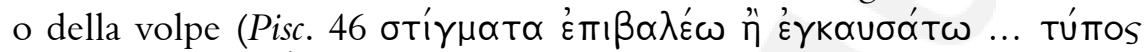
Toû kauTñpos). È questo in sostanza ciò che la satira produce.

Come gli eroi del mito e più ancora come quelli della Commedia, anche l'eroe satirico diviene un euergetes proprio attraverso quello che dice - e non attraverso quello che fa come l'eroe comico. ${ }^{126}$ Non è sempre facile comprendere che si tratta di un merito, ma questa gloria egli se la conquista per l'appunto attraverso lo smascheramento dello pseudos e la ricerca dell'aletheia, ${ }^{127}$ tra molti pericoli e sempre senza alcuna paura o inibizione. Solenne è qui il riconoscimento, ma le cose vanno così solo

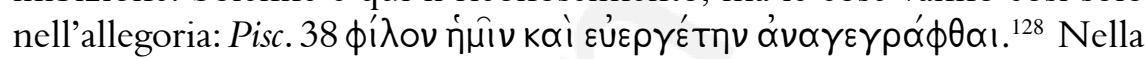
realtà della comunicazione è nell'applauso e nel riso del pubblico che si decreta il successo e il significato della parola satirica.

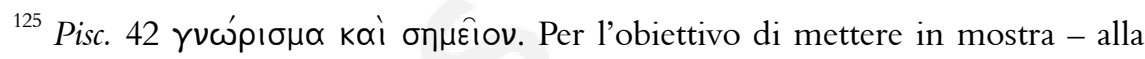
berlina - di fronte a tutti il bersaglio dell'attacco cf. anche l'azione di Pisc. 48

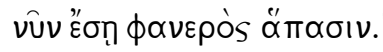

${ }^{126}$ Analogo valore ha la $\phi ı \lambda \propto \nu \theta \rho \omega \pi i ́ \alpha$ del filosofo cinico - che convive con la sua misantropia - nei confronti di tutti gli uomini proprio attraverso la sua funzione di kataskopos che osserva i mali per poi descriverli e smascherarli (cf. Moles, op. cit.). Così Diogene si definisce "liberatore" e "guaritore" del genere umano proprio a

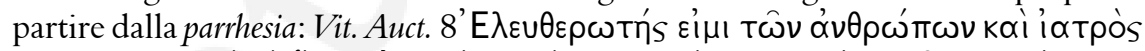

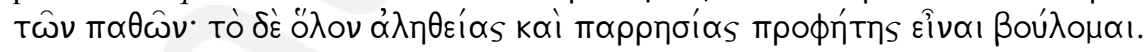
In questo segue il modello eroico di Eracle e l'effetto della sua azione satirica e

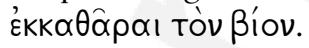

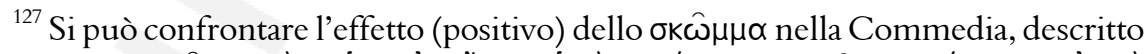

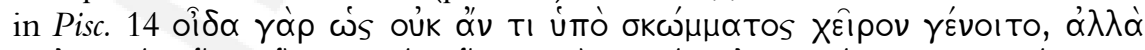

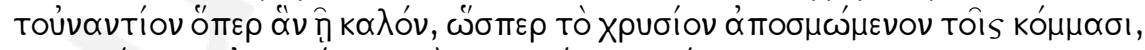

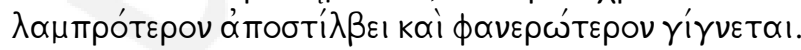

${ }^{128}$ Cf. anche all'inizio la dichiarazione d'intenti di Parresiade, secondo il quale la

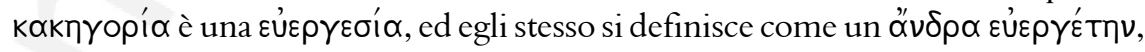
degno di elogio e non di ostilita per i ponoi che ha affrontato (Pisc. 5). 


\section{II riso o la via breve alla satira}

Nella satira il riso è fenomeno onnipresente. Nelle opere di Luciano è raro il riso festivo, il riso dell'entusiasmo collettivo e di gioia che invece ha parte rilevante nella Commedia, ${ }^{129}$ in particolare nel trionfo dell'eroe comico e nel successo della sua impresa. Così vale anche per il sorriso. ${ }^{130}$ Nella satira il $\gamma^{\varepsilon} \lambda \omega s$ è un riso critico, che ha l'effetto di trasformare il suo oggetto e lo riduce al $\gamma \varepsilon \lambda \hat{o ̂}$ ov e al disprezzo. ${ }^{131} \grave{\mathrm{E}}$ strumento principe dell'attacco, che agisce in maniera semplice e potentissima, ed è incontrovertibile, ossia al riso non v'è possibilità di replica. ${ }^{132} \grave{E}$ anche strumento filosofico ed etico, che giunge ad essere per l'eroe satirico virtù ${ }^{133}$ e segno distintivo, ${ }^{134}$ cifra di riconoscimento ${ }^{135}$

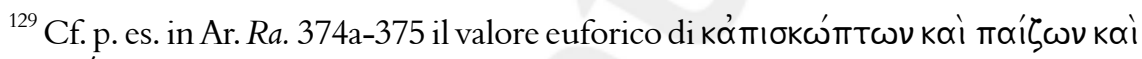
$\chi \lambda \varepsilon \varepsilon \alpha^{\prime} \zeta \omega \nu$ (e così ai vv. 389-393). L'attacco satirico e il riso della satira invece

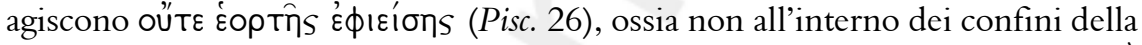
festa come avveniva per la Commedia e come è spiegato da Luciano in Pisc. 25: kå

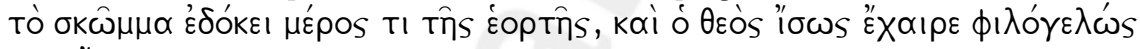

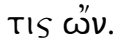

${ }^{130}$ Cf. Husson, op. cit., p. 178 ss., la quale presenta nella sua indagine sul riso in Luciano anche qualche esempio di riso o sorriso diverso da quello critico. Per le diverse tipologie di riso nella Commedia, cf. Sommerstein, op. cit., p. 68-75.

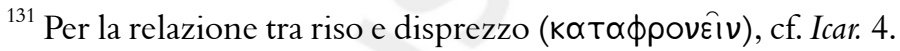

${ }^{132}$ Di fronte al riso non v'è rimedio e non è possibile replicare né annullarne gli effetti, nonostante Luciano ci proponga dei dubbi in proposito. Ma anche la valutazione in questo senso di Diogene per il riso di Menippo è piuttosto una

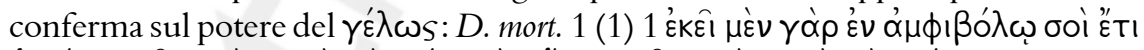

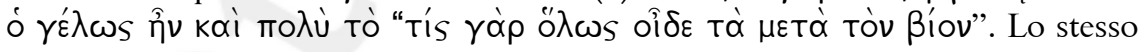
Luciano teme gli effetti del riso, cf. Pseudol. 8.

${ }^{133}$ Il riso è nel catalogo delle specifiche virtù ciniche e satiriche di Menippo, D. mort. 20 (10) 9. Cf. supra n. 120.

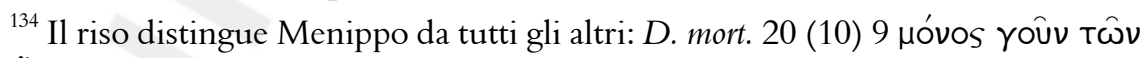
$\alpha^{\prime \prime} \lambda \lambda \omega \nu \gamma \varepsilon \lambda \hat{\alpha}_{s}$. Cf. anche D. mort. 4 (21) 2 per Menippo e Diogene.

${ }^{135} \mathrm{Il}$ riso è tra i segni che permettono di riconoscere inequivocabilmente Menippo, il quale a Corinto o ad Atene non fa altro che ridere dei filosofi in contesa tra di

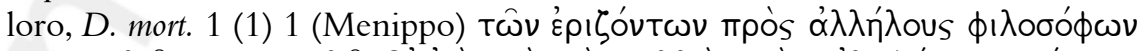

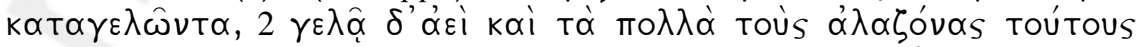

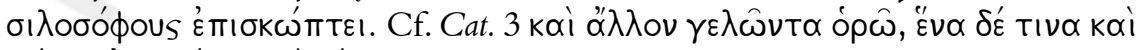

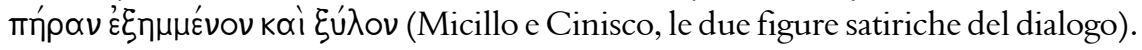


e principio di vita: ${ }^{136}$ anzi il suo riso non ha termine neppure nell'Aldilà dopo la morte. ${ }^{137}$ Losservazione vede e descrive, il riso è conseguente alla visione ed è strumento che distrugge tutto ciò che tocca.

Ma come agisce nel concreto questo riso critico e quali sono i suoi effetti? Esso sancisce uno smascheramento e un vero e proprio rovesciamento nella scala dei valori. Le cose più ambite secondo le convenzioni sociali e che sono considerate falsamente serie, importanti, preziose vengono smascherate dall'osservazione satirica e rovesciate nel loro opposto: esse si rivelano piccole, meschine, inconsistenti, insicure. Si può prendere come paradigma dell'azione l'immagine delle statue che il tiranno ha innalzato a se stesso come segno della sua grandezza e della sua potenza quando esse vengono abbattute e rovesciate:

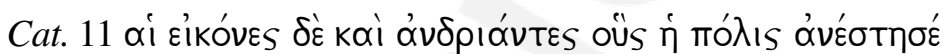

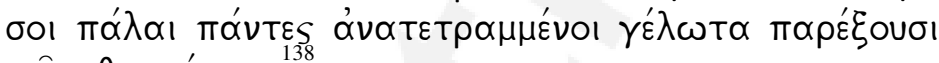
Tôs $\theta \varepsilon \omega \mu \varepsilon^{\prime}$ oIs.

Tutto ciò che nell'opinione comune sta più in alto diviene il bersaglio preferito e naturale della satira, e attraverso il riso viene fatto precipitare in basso, perché ritorni in sostanza tra gli uomini. La vita umana all'occhio normale non pone dubbi né rivela fratture per abitudine o per paura, ma per l'occhio della satira la realtà quotidiana è coperta da una maschera al di là della quale l'eroe satirico sa e deve vedere. ${ }^{139}$ Il riso toglie questa maschera

${ }^{136}$ Secondo la regola etica rivelata da Tiresia a Menippo in Nec. 21: $\gamma \varepsilon \lambda \hat{\omega} \nu$ tà

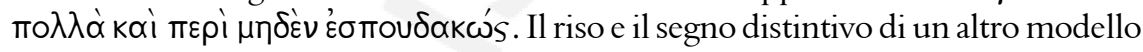
per Luciano della disposizione critica, il filosofo atomista Democrito (Vit. Auct. 13

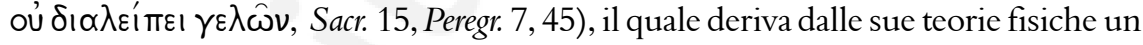
atteggiamento simile a quello che Tiresia consiglia a Menippo: Vit. Auct. $13 \mu \mathrm{ol}$

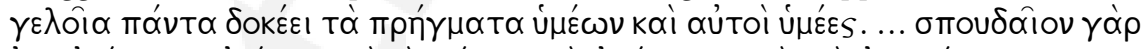

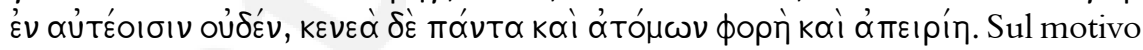
del riso come principio per la condotta di vita cf. Desclos, op. cit.

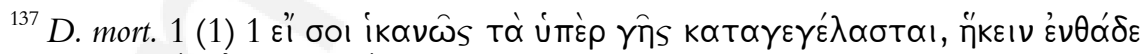

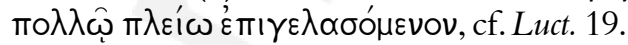

138 "Le immagini e le statue che la città un tempo ti innalzò saranno tutte abbattute e faranno ridere coloro che le vedranno". Per l'immagine della statua rovesciata, con i significati critici, cf. Pro imag. 11.

${ }^{139}$ Il dovere dell'osservazione, con gli occhi e con le orecchie, è definito sulle tracce del modello epico di Odisseo (e anche in questo caso al di là di esso) in Nigr. 19. Ma resta comunque cosa difficile e rara, perché pochi sono coloro che hanno la vista e l'udito dell'eroe satirico (Cont. 21). 
protetta dall'opinione accettata e rivela a tutti la verità. Lo scarto tra l'apparenza esteriore e la realtà smascherata scatena il riso: più grande è lo scarto rivelato e più terribile è l'effetto. ${ }^{140} \mathrm{Il} \gamma \dot{\varepsilon} \lambda \omega$ S entra in azione proprio in coincidenza di questo svelamento ed è manifestazione critica di attacco, spontanea, immediata, irrefrenabile e inarrestabile, ${ }^{141}$ rivolta contro il bersaglio che è preso di mira. Esso è arma che scardina le sicurezze dell'avversario e diviene al tempo stesso piacere per l'eroe satirico, ${ }^{142}$ perché rappresenta il culmine dell'azione personale e coincide con il successo dell'impresa satirica - come della performance dell'autore -, proprio mentre produce e dichiara la débâcle di chi viene attaccato. A questo punto l'oggetto del $\gamma \hat{\varepsilon} \lambda \omega s$ è definito pubblicamente e universalmente come ridicolo. Per questo l'effetto è sconvolgente, senza scampo e senza ritorno, e perciò è

${ }^{140}$ Ciò che avviene con lo smascheramento e la rivelazione dello scarto è messo in

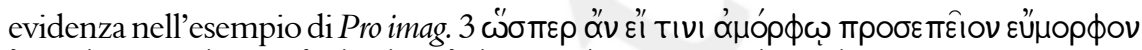

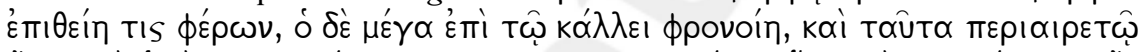

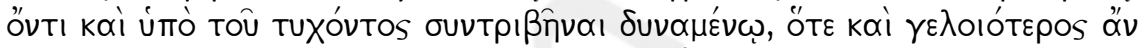

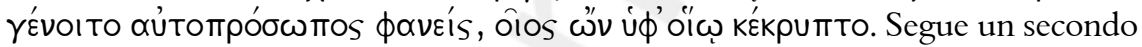
esempio relativo alla falsificazione della statura.

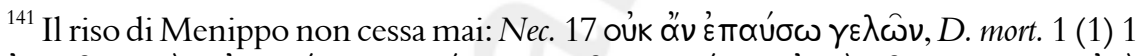

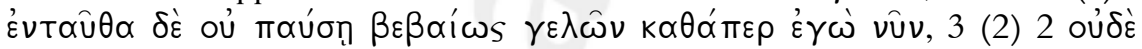

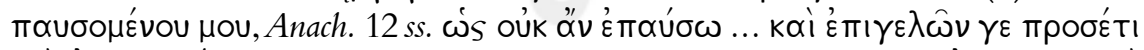

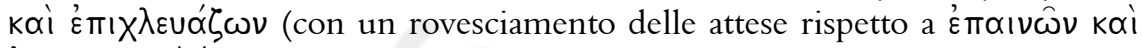

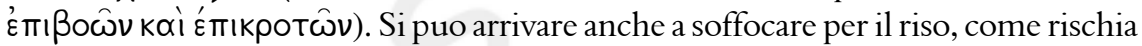

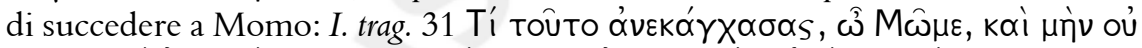

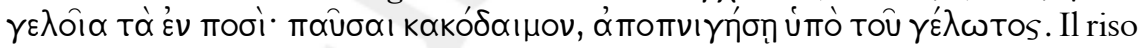

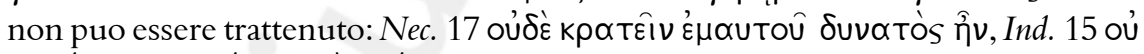

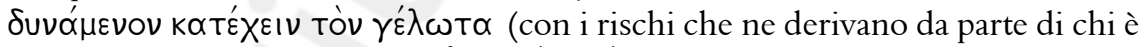

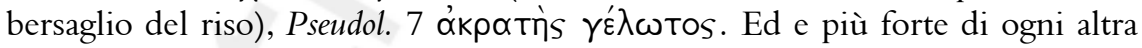
emozione, anche di quelle che di norma lo inibiscono (cf. Sacr. 1). Per un precedente comico del motivo cf. p. es. ciò che capita a Eracle davanti alle incongruenze del

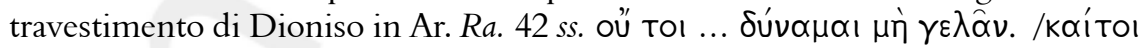

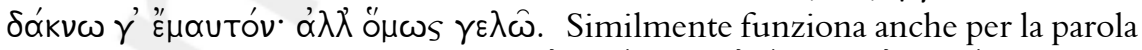

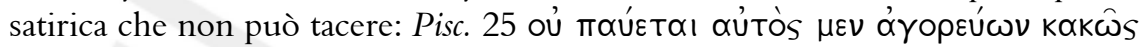

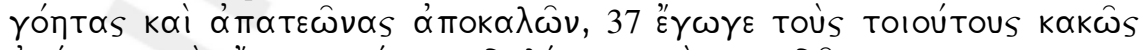

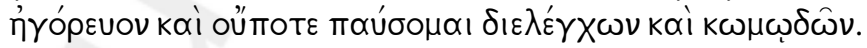

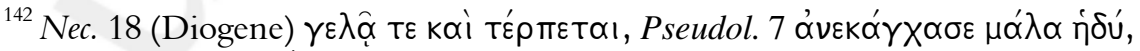

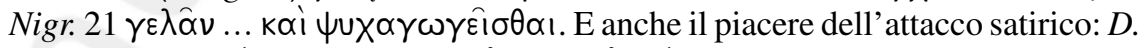

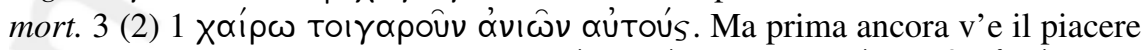

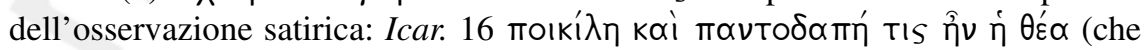

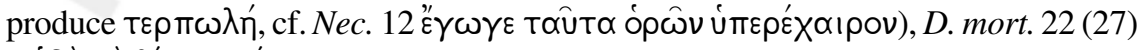

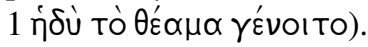


temuto e suscita l'ostilità in chi ne è colpito contro l'autore della satira o di volta in volta contro il suo porte-parole, ${ }^{143}$ proprio come avviene per lo scherno e per l'ingiuria. ${ }^{144}$

Il riso infatti è anche strumento potentissimo di comunicazione che nella satira come nella commedia agisce in un sistema a tre termini: ${ }^{145}$ il soggetto che ride, l'oggetto o bersaglio del riso, e il pubblico, sdoppiato nel pubblico interno al testo (come per esempio il personaggio che ascolta il racconto di Menippo) e il pubblico più ampio che assiste alla performance di Luciano o che legge le sue opere. Il riso è segno inequivocabile e immediato nella percezione, contiene una forza contagiosa e persuasiva straordinaria, e perciò coinvolge immediatamente in una sympatheia totale il pubblico della satira che fa da testimone e diviene direttamente partecipe proprio attraverso il riso del processo di smascheramento. ${ }^{146}$ Senza questo coinvolgimento la satira non funziona, il pubblico deve diventare soggetto attivo allo stesso modo dell'eroe satirico e dell'autore. Tra le strategie della partecipazione il riso è senz'altro la più efficace. ${ }^{147}$

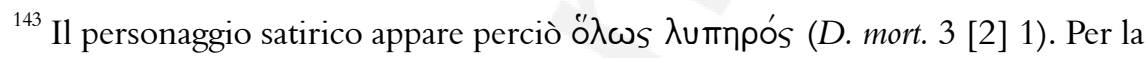
reazione di ostilità contro il riso cf. Pseudol. 7. Come si è visto sopra, Parresiade, il protagonista del Piscator, per i suoi attacchi satirici, che comprendono anche il riso

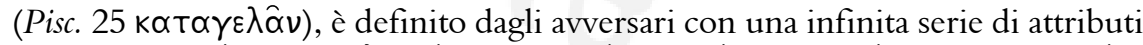

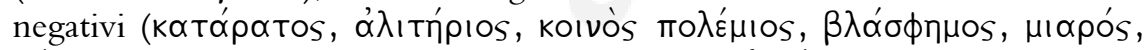

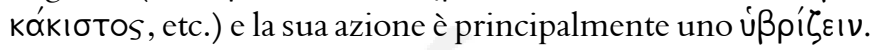

${ }^{144}$ Per il contatto tra riso, motteggio e ingiuria nell'attacco satirico cf. p. es. D. mort.

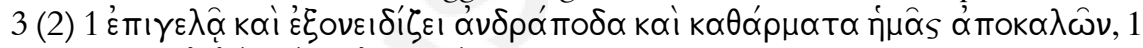

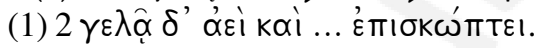

${ }^{145}$ Per una valutazione semiotica del sistema d'azione a tre termini del riso nei testi antichi cf. Pellizer, op. cit., p. 51.

${ }^{146}$ Ciò che avviene è con precisione definito da Luciano sulle tracce della Commedia,

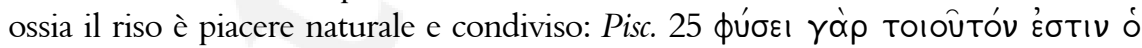

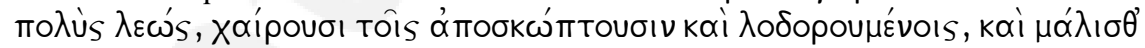

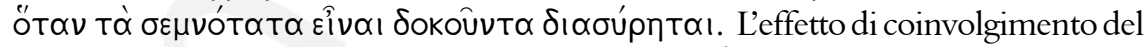

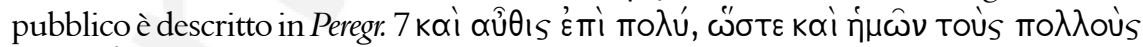

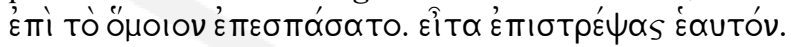

${ }^{147}$ Cf. Whitmarsh, op. cit., p. 472: "When narratees laugh, they join with 'Lucian' or his alter ego, united against a common target: the text thus effects a reincorporation of community through satirical mockery". Valutazioni analoghe sulle strategie di coinvolgimento del destinatario si possono fare, pur nei termini diversi, per lo skomma e la parodia, che implicano una attiva collaborazione del destinatario e con essa la sua partecipazione diretta alle logiche del testo e della comunicazione (cf. in proposito Camerotto, op. cit., 1998, p. 277-302). 
Vediamo come esempio ciò che avviene nell'Icaromenippo. Nell'impresa del volo di Menippo il riso sta al principio. Se guardiamo il testo possiamo dire che tutto inizia dal riso, e nel riso tutto si compie.

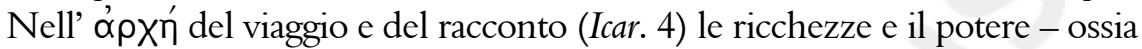
le cose che nella vita sono ritenute come le più importanti tanto da impegnare totalmente e ciecamente le passioni degli uomini - appaiono a Menippo $\gamma \varepsilon \lambda \hat{\imath} \alpha$ fin dalla prima indagine, e le ragioni che generano il riso

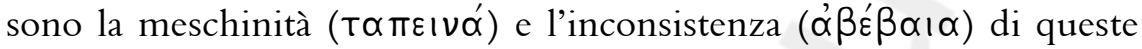
ambizioni con un rovesciamento totale della scala dei valori convenzionali. Il riso è già in azione nel protagonista che cerca di guardare più in là delle apparenze e che ancora prima di trovare la sua specola satirica vede le incongruenze dei desideri umani e soprattutto avverte la discrepanza rispetto a ciò che è veramente importante nella vita.

$\mathrm{Al}$ secondo passo del percorso, i filosofi gettano Menippo in una aporia ancor maggiore con le loro contraddizioni e provocano il riso al momento in cui si rivela al protagonista lo scarto tra le loro arroganti pretese e la verità. Essi vorrebbero stare al di sopra degli altri uomini per la loro sapienza fino ad apparire come dei. Non camminano più sulla terra come fanno di necessità i comuni mortali e pretendono di vedere anche ciò che sta in cielo e che è lontanissimo dalla loro portata. La verità, dalla quale scaturisce immediato il riso, è invece che questi falsi filosofi sono ciechi e la loro scienza non è altro che ciarlataneria e

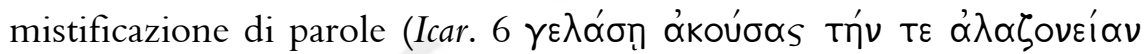

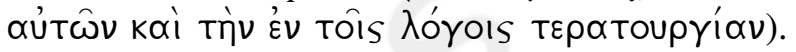

Di nuovo, ma con un ampliamento delle prospettive e una moltiplicazione dei bersagli, il riso entra in azione quando Menippo inizia l'osservazione satirica dalla luna. Si presentano ai suoi occhi ormai divenuti potentissimi i vizi e i misfatti segreti dei sovrani e dei potenti (Icar. 15): è una sequenza di azioni ridicole nella loro tragicità per il rovesciamento delle apparenze contenuto nella serie infinita di tradimenti e di uccisioni dei congiunti e delle persone più fidate, e per la banalità e la bassezza della violenza. Ma non meno fanno ridere le azioni degli uomini comuni (Icar.

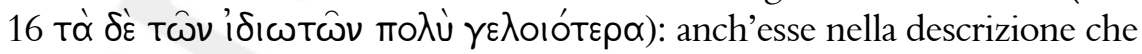
ne dà l'osservatore satirico sono tutte fondate sullo smascheramento delle finte virtù, in particolare quelle di singoli filosofi e retori ritratti nei loro vizi. A rappresentare la disarmonia ( $\alpha \dot{\nu} \propto \rho \mu o \sigma \tau i \alpha)$ della vita umana, Menippo propone l'immagine dei cori di voci discordi che si sovrappongono per

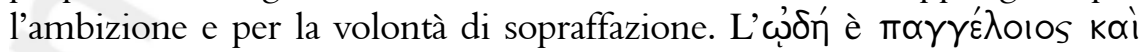

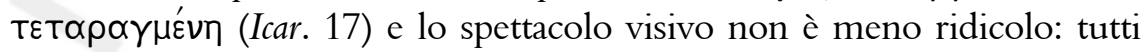
pretendono di sfoggiare la loro veste e di compiere i loro movimenti sulla

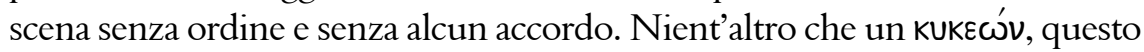


è il mondo degli uomini. Ma la vita è un attimo, la morte con la sua isotimia forse distopica arriva a spazzare ogni superbia e a far tacere i protagonisti di

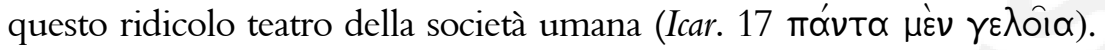

Dallo sguardo sul mondo che segue, il riso nasce per il gioco delle proporzioni. Ciò che agli uomini appare sulla terra così grande e così prezioso si riduce sistematicamente a un nulla: lo stesso nostro pianeta appare piccolissimo e quasi irriconoscibile nel cosmo, gli uomini sono come formiche e non più che formicai sono le città. Le continue contese e $\mathrm{i}$ conflitti dei mortali per la grandezza delle loro proprietà e per l'estensione dei domini perdono ogni senso quando dall'alto l'intera Grecia si riduce a una misura di quattro dita, e in proporzione i latifondi dei ricchi non risultano più grandi di un atomo di Epicuro. ${ }^{148}$ Così si riduce alle dimensioni di una lenticchia anche l'intera regione di Cinosura, per la quale in una guerra assurda, descritta da Erodoto, sono morti tanti Spartani e Argivi. E il riso si rinnova al pensiero di come ci si insuperbisce sulla terra per il possesso dell'oro, ${ }^{149}$ quando dalla luna l'intero monte Pangeo con le sue miniere non è più grande di un chicco di miglio. A questo punto - come abbiamo anticipato - non è più paradossale il volo di Menippo, ma lo è invece l'assurdità di ciò che rivela la visione satirica, la quale smaschera la piccolezza delle cose umane: di qui, a partire dalla visione, si genera il riso, ${ }^{150}$ ossia dal confronto e dalla verifica dello scarto tra l'opinione comune e la verità della satira.

Il riso alla fine, dall'alto delle sedi degli dei, ritorna sui filosofi, il bersaglio più importante dell'Icaromenippo. Nell'assemblea divina convocata proprio grazie all'impresa del nostro eroe satirico - è lo stesso Zeus che deve decidere che cosa fare di questa schiatta piena di vizi e omericamente "inutile peso della terra", ${ }^{151}$ divisa in sètte in contraddizione e in contesa perenne tra di loro e dai nomi uno più

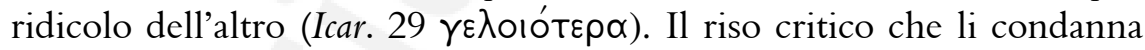

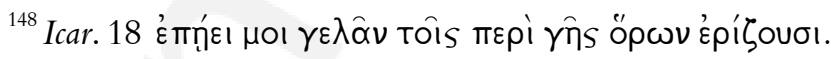

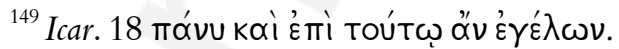

${ }^{150} \mathrm{La}$ sequenza osservazione satirica-riso si presenta regolarmente ed è sottolineata

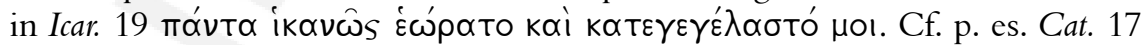

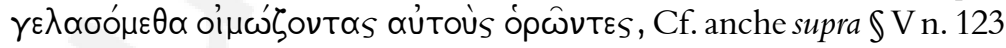

${ }^{151} \mathrm{Cf}$. il cumulo comico-satirico di attributi negativi (e ingiuriosi) concluso dalla

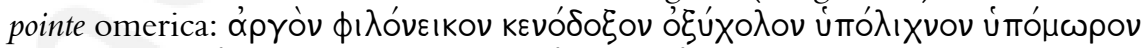

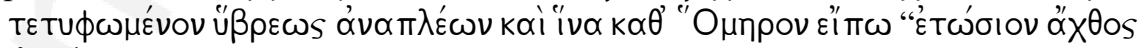
ápoúpns" (Icar. 29).
} 
nasce in particolare dallo svelamento della loro doppiezza. Sono filosofi solo nell'aspetto esteriore, fatto dei vuoti segni delle lunghe barbe e del contegno austero, e recitano così la superba parte della virtù con la quale nascondono la depravazione e i misfatti. Ancora con un'immagine teatrale, essi non sono altro che attori, ai quali se si toglie loro la maschera e lo sfarzo della veste, non rimane nulla più che la meschina realtà di

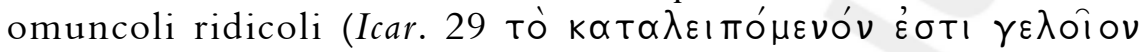

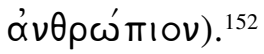

\section{Riferimenti}

AMMENDOLA, S. Limitazioni del diritto di libertà di parola nell'Atene del V secolo ed in particolare nel teatro attico. AION (sez.fil.-lett.), Napoli, vol. 23, p. 41113,2001.

ANDERSON, G. Lucian: theme and variation in the Second Sophistic. Leiden: Brill, 1976.

BASLEZ, M. F. Voyager au-delà: la symbolique du voyage dans la pensée grecque. In: DUCHÊNE, H. (org.). Voyageurs et Antiquité classique. Dijon: EUD, 2003, p. 87100.

BERNARDINI, P. A. Greci e Sciti nell'opera di Luciano: due culture a confronto. In: FINIS, L. (org.). Civiltà classica e mondo dei barbari: due modelli a confronto. Trento: Associazione italiana di cultura classica Trento, 1991, p. 171-183.

BERNARDINI, P. A. L'agonismo sportivo dei greci e lo stupore dei barbari. In: BETTINI, M. (org.). Lo straniero ovvero l'identità culturale a confronto. Roma/ Bari: Laterza, 1992, p. 39-49.

BERNARDINI, P. A. Luciano: Anacarsi. A cura di P. Angeli Bernardini. Pordenone: Biblioteca dell'Immagine, 1995.

${ }^{152}$ I filosofi che sono bersaglio della satira lucianea non fanno altro che indossare una veste teatrale della filosofia, per recitare una $\tau \rho \alpha \gamma \omega \delta \delta^{\prime} \alpha$ esteriore alla ricerca

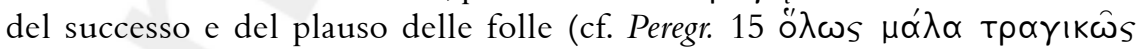

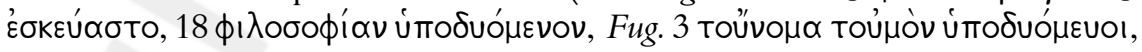
Nigr. 24, cf. Clay, op. cit., p. 3417 s. in relazione alla cultura teatralizzata dell'epoca). Luciano li spoglia dell'apparato esteriore per rivelare i loro vizi. Le azioni dello smascheramento sono sottolineate in particolare nell'immagine teatrale di Nec. 16:

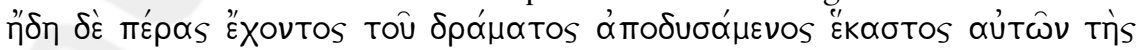

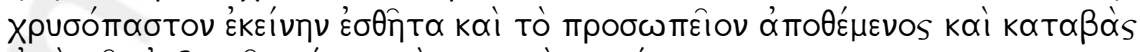

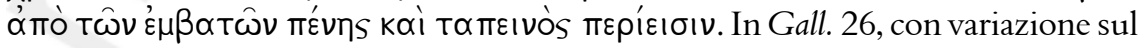
motivo, v'è la caduta e lo smascheramento dell'attore tragico come paradigma in questo caso per la vuota grandezza dei re. 
BILLERBECK, M. The ideal cynic from Epictetus to Julian. In: BRANHAM, R. B.; GOULET-CAZÉ, M. O. (org.). The Cynics: the Cynic movement in antiquity and its legacy. Berkeley: University of California Press, 1996, p. 205-221.

BOSMAN, P. Selling Cynicism: the pragmatic of Diogenes' comic performances. Classical Quarterly, Oxford, vol. 56, p. 93-104, 2006.

BRANHAM, R. B. Unruly eloquence: Lucian and the comedy of traditions. Cambridge, Mass./ London: Harvard University Press, 1989.

BRANHAM, R. B. Defacing the currency: Diogenes' rhetoric and the invention of Cynicism. Arethusa, New York, vol. 27, p. 329-360, 1994.

CAMEROTTO, A. Le metamorfosi della parola: studi sulla parodia in Luciano di Samosata. Pisa/ Roma: Istituti Editoriali e Poligrafici Internazionali, 1998.

CAMEROTTO, A. Come diventare un eroe: le virtù e le imprese di Trygaios Athmoneus. Incontri triestini di filologia classica, Trieste, vol. 6, p. 257-287, 2006-2007.

CAMEROTTO, A. Luciano di Samosata: Icaromenippo. A cura di A. Camerotto. Alessandria: Edizioni dell'Orso, 2009a.

CAMEROTTO, A. Fare gli eroi. Le storie, le imprese, le virtù: composizione e racconto nell'epica greca arcaica. Padova: Il Poligrafo, 2009.

CISTARO, M. Sotto il velo di Pantea: "Imagines" e "Pro imaginibus" di Luciano. Messina: Dipartimento di Scienze dell'Antichità, 2009b.

CLAY, D. Lucian of Samosata: four philosophical lives (Nigrinus, Demonax, Peregrinus, Alexander Pseudomantis). In : ANRW II. Vol. 36, n. 5. Berlin/ New York: De Gruyter, 1992, p. 3406-3450.

DESCLOS, M. L. Le rire comme conduite de vie: l'Ésope de Platon. In: DESCLOS, M. L. (org.). Le rire des Grecs: anthropologie du rire en Grèce ancienne. Grenoble: Millon, 2000, p. 441-457.

DESMOND, W. Cynics. Stocksfield: Acumen, 2008.

DOLCETTI, P. Personificazioni, scelte di vita e scelte letterarie nell'opera di Luciano. Quaderni del Dipartimento di Filologia Linguistica e Tradizione classica, Torino, p. 245-261, 1997.

DUBEL, S. Dialogue et autoportrait: le masques de Lucien. In: BILLAULT, A. (org.). Lucien de Samosate: Actes du Colloque de Lyon (septembre 1993). Lyon: De Boccard, 1994, p. 19-26.

FOUCAULT, M. Discorso e verità nella Grecia antica. Roma: Donzelli, 1996 (Discourse and truth: the problematization of parrhesia, 1985).

FRYE, N. Anatomia della critica. Torino: Einaudi, 1969 (Anatomy of criticism. Princeton: Princeton University Press, 1957).

GEORGIADOU, A.; LARMOUR, D. H. J. Lucian's science fiction novel “True Histories”: interpretation \& commentary. Leiden/ Boston/ Köln: Brill, 1998.

GIANNANTONI, G. Socratis et Socraticorum reliquiae: I-IV. Napoli: Bibliopolis, 1985-1990. 
GOULET-CAZÉ, M. O. L'ascèse cynique: un commentaire de Diogène Laërce VI 70-71. Paris: Vrin, 1986.

HABASH, M. Dionysos' roles in Aristophanes' "Frogs". Mnemosyne, Amsterdam, vol. 55, p. 1-17, 2002.

HALL, J. A. Lucian's Satire. New York: Arno Press, 1981.

HUSSON, G. Lucien philosophe du rire ou "Pour ce que rire est le propre de l'homme". In: BILLAULT, A. (org.). Lucien de Samosate: Actes du Colloque de Lyon (septembre 1993). Lyon: De Boccard, 1994, p. 177-184.

JACOBSON, H. Lucian's Charon and the "Odyssey". MD, Pisa, vol. 43, p. 221-222, 1999.

JONES, C. P. Culture and society in Lucian. Cambridge, Mass./ London: Harvard University Press, 1986.

LANZA, D. Lo stolto: di Socrate, Eulenspiegel, Pinocchio e altri trasgressori del senso comune. Torino: Einaudi, 1997.

LICHACËV, D. S. La rivolta del "mondo delle tenebre". Strumenti critici, Torino, vol. 14, p. 333-346, 1980.

MCCARTHY, B. P. Lucian and Menippus. YCS, Cambridge, vol. 4, p. 3-58, 1934. MOLES, J. Le cosmopolitisme cynique. In: GOULET-CAZÉ, M. O.; GOULET, R. (org.). Le Cynisme ancien et ses prolongements. Paris: Presses Universitaires de France, 1993, p. 259-280.

MOMIGLIANO, A. La libertà di parola nel mondo antico. Rivista storica italiana, Napoli, vol. 83, p. 499-524, 1971.

PELLIZER, E. Formes du rire en Grèce antique. In: DESCLOS, M. L. (org.). Le rire des Grecs: anthropologie du rire en Grèce ancienne. Grenoble: Millon, 2000, p. 45-55.

RADIN, M. Freedom of speech in ancient Athens. AJPh, Baltimore, vol. 48, p. 215230, 1927.

RELIHAN, J. C. Vainglorious Menippus in the "Dialogues of the Dead". ICS, Ithaca N.Y., vol. 12, p. 185-206, 1987.

RELIHAN, J. C. Menippus, the cur from Crete. Prometheus, Firenze, vol. 16, p. 217224, 1990.

RELIHAN, J. C. Relihan, Menippus in antiquity and the Renaissance. In: BRANHAM, R.; GOULET-CAZÉ, M. O. (org.). The Cynics: the Cynic movement in antiquity and its legacy. Berkeley: University of California Press, 1996, p. 265293.

SAÏD, S. Lucien ethnographe. In: BILLAULT, A. (org.). Lucien de Samosate: Actes du Colloque de Lyon (septembre 1993). Lyon: De Boccard, 1994, p. 149-170.

SCARPAT, G. Parrhesia: storia del termine e delle sue traduzioni in latino. Brescia: Paideia, 1964. 
SLUITER, I.; ROSEN, R. M. General introduction. In: SLUITER, I.; ROSEN, R. M. (org.). Free speech in Classical antiquity. Leiden/ Boston: Brill, 2004, p. 1-19.

SOMMERSTEIN, A. Parler du rire chez Aristophane. In: DESCLOS, M. L. (org.). Le rire des Grecs: anthropologie du rire en Grèce ancienne. Grenoble: Millon, 2000, p. 65-75.

SPINA, L. Il cittadino alla tribuna: diritto e libertà di parola nell'Atene democratica. Napoli: Liguori, 1986.

SPINA, L. "Parrhesia" e retorica: un rapporto difficile. Paideia, Firenze, vol. 60, p. 317-346, 2005.

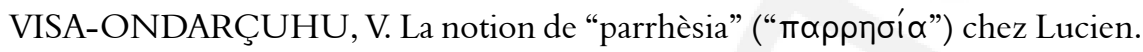
Pallas, Toulouse, vol. 72, p. 261-268, 2006.

WHITMAN, C. H. Aristophanes and the comic hero. Cambridge, Mass.: Harvard University Press, 1964.

WHITMARSH, T. J. G. Lucian. In: DE JONG, I.; NÜNLIST, R.; BOWIE, A. (org.). Narrators, narratees, and narratives in Ancient Greek Literature: studies in Ancient Greek Narrative. Vol. I. Leiden/ Boston: Brill, 2004, p. 465-476. 